\title{
Silane grafted natural rubber and its compatibilization effect on silica-reinforced rubber tire compounds
}

\author{
K. Sengloyluan ${ }^{1,2}$, K. Sahakaro ${ }^{1 *}$,W. K. Dierkes $^{2}$, J. W. M. Noordermeer ${ }^{2}$ \\ ${ }^{1}$ Department of Rubber Technology and Polymer Science, Faculty of Science and Technology, Prince of Songkla \\ University, 94000 Pattani, Thailand \\ ${ }^{2}$ Elastomer Technology and Engineering, Department of Mechanics of Solids, Surfaces and Systems (MS3), Faculty of \\ Engineering Technology, University of Twente, P.O. BOX 217, 7500AE Enschede, The Netherlands
}

Received 28 April 2017; accepted in revised form 22 July 2017

\begin{abstract}
Natural Rubber (NR) grafted with 3-octanoylthio-1-propyltriethoxysilane (NXT) was prepared by melt mixing using 1,1'-di(tert-butylperoxy)-3,3,5-trimethylcyclohexane as initiator at $140^{\circ} \mathrm{C}$ with $\mathrm{NXT}$ contents of 10 and 20 parts per hundred rubber $[\mathrm{phr}]$ and initiator $0.1 \mathrm{phr}$. The silane grafted on NR molecules was confirmed by Fourier transform infrared (FTIR), proton nuclear magnetic resonance $\left({ }^{1} \mathrm{H}-\mathrm{NMR}\right)$ and scanning electron microscopy/energy dispersive X-ray spectroscopy (SEM-EDX). Based on ${ }^{1} \mathrm{H}-\mathrm{NMR}$, the use of 10 and $20 \mathrm{phr}$ (parts per hundred resin) of silane resulted in grafted NXT onto NR of 0.66 and $1.32 \mathrm{~mol} \%$, respectively, or a grafting efficiency of approx.38\%. The use of NXT-grafted NR as compatibilizer in silica-filled NR compounds, to give a total amount of NXT in both grafted and non-grafted forms in the range of $0.8-6.1 \mathrm{wt} \%$ relative to the silica, decreases the Mooney viscosity and Payne effect of the compounds, improves filler-rubber interaction, and significantly increases the tensile properties of the silica-filled NR-compounds compared to the non-compatibilized one. At the same silane-content, the use of silane-grafted NR gives slightly better properties than the straight use of the same silane. With sulfur compensation, the use of NXT-grafted-NR with about $6 \mathrm{wt} \%$ NXT relative to the silica gives technical properties that reach the levels obtained for straight use of bis-(3-triethoxysilyl-propyl)tetrasulfide (TESPT) at $8.6 \mathrm{wt} \%$ relative to the silica.
\end{abstract}

Keywords: rubber, reinforcement, natural rubber, silica, silane grafted NR

\section{Introduction}

Silica has a hydrophilic surface by its specific character of a large number of surface silanol groups, i.e. $4.9 \mathrm{OH} \cdot \mathrm{nm}^{-2}[1]$, leading to strong hydrogen bonding between silica particles and poor filler-rubber interactions in non-polar elastomers. In general, a silane coupling agent is added together with silica into a rubber during the mixing process to enhance the silica-rubber compatibility. Under suitable mixing conditions, the silane coupling agent undergoes a silanization reaction with silanol groups on the silica involving primary and secondary reactions [2]. To complete the reaction between silica and, for example, bis-(3-triethoxysilylpropyl)tetrasulfide (TESPT) silane during mixing, the discharge temperature of a silicafilled Styrene-Butadiene Rubber (SBR) compound should be above $130^{\circ} \mathrm{C}$. But at a temperature above $160^{\circ} \mathrm{C}$ the silane starts to react with the elastomer to form premature crosslinks [3]. For silica-filled NR compounds with TESPT as coupling agent, a discharge temperature is recommended in the range of $135-150^{\circ} \mathrm{C}$ while a higher temperature leads to degradation of the NR [4]. All silanes with alkoxy functional groups may react with the silanol groups on the silica and so shield the silica surface to make it more hydrophobic [5]. Different silanes show distinct 
effects on the properties of silica-filled elastomers. A sulfur-free silane shows a good improvement in the Payne effect, but gives poorer mechanical and dynamic mechanical properties compared to sulfurcontaining silanes such as TESPT [6].

Surface modification of silica prior to mixing is an alternative method to improve silica reinforcement in the rubber matrix. Modification of silica with a silane coupling agent can change the characteristic surface from hydrophilic to hydrophobic. Surface modification with vinyl- and mercapto-silanes reduces the silica aggregate size without re-agglomeration of the silica, but modification with an aminosilane tends to increase the silica agglomerate size because of its hydrophilicity that leads to the formation of hydrogen bonds between particles/aggregates $[7,8]$. Organic monomers such as styrene, isoprene, and butadiene have been used to modify the silica surface to obtain a hydrophobic character through in situ polymerization of the monomers adsorbed on the surface via bilayers of surfactants [9-11].

Silane-modified polymers are another route employed for improvement of silica reinforcement in polymeric materials. Polypropylene (PP) grafted with vinyltriethoxysilane (VTES) was used in PP/silica nanocomposites in which the grafted PP could attach to the silica surface through VTES moieties, leading to a decrease of chain mobility and diffusion, as proven by a shift of crystallization and melting behaviors to a higher temperature [12]. The use of VTES-grafted SBR for a silica-filled compound led to improved cure and tensile properties $[13,14]$, and a shift of the glass transition temperature [13] $\left(T_{\mathrm{g}}\right)$ to a higher temperature due to the good interactions between silica and SBR-graft-VTES, that restrict movement of the SBR chains. A liquid low molecular weight polybutadiene (PB) was grafted with mercaptopropyltrimethoxysilane through radical addition of the thiol group to the double bonds on the polymer molecule at $75^{\circ} \mathrm{C}$. The grafted $\mathrm{PB}$ was later silanized onto silica surfaces at $135^{\circ} \mathrm{C}$, allowing the alkoxy-groups of the silane fragments to react with the silanol groups of the silica [15]. Modified-silica with the grafted $\mathrm{PB}$ showed a decrease in the number of $\mathrm{OH}$-groups on the surface to the same level as that of silica with TESPT, due to the influence of the shielding effect of the grafted PB. The decrease of hydrophilic character of the surface modified silica further lead to a reduction of filler-filler interaction and an improvement of filler dispersion in the rubber matrix [16].
Grafting of silane onto polymers has been reported employing different reaction conditions. Silane grafted onto polybutadiene was done in solution under nitrogen atmosphere [15-17]. The solution state is known to provide a better control of the reaction compared to the melt state, but is environmentally unfriendly and provides only a small amount of grafted polymer per batch. The reaction in solution is therefore not preferred for industrial scale. VTES grafted onto SBR has been studied in the latex state using benzoic peroxide as initiator [13]. Furthermore, silane grafting in the melt state is well known for vinylsilane-grafted polyolefins like polyethylene [18-20] and polypropylene [21].

Grafting of 3-octanoylthio-1-propyltriethoxysilane (NXT) onto NR molecules is done in the present work. For practical purposes, the NXT-grafted-NR is prepared by melt mixing in an internal mixer using 1,1'-di(tert-butylperoxy)-3,3,5-trimethylcyclohexane or Luperox ${ }^{\circledR} 231 X L 40$ as an initiator. The half-life time of Luperox ${ }^{\circledR} 231$ at $140^{\circ} \mathrm{C}$ is about 5 minutes which is shorter than that of the more common dicumyl peroxide (DCP) with its half-life time of about 30 minutes at the same temperature. The shorter half-life time of Luperox ${ }^{\circledR} 231$ allows the grafting process to be conducted at lower temperature and shorter reaction time compared to the use of DCP, to prevent thermal degradation of the NR. Prior optimization of grafting conditions gave an optimal temperature of $140^{\circ} \mathrm{C}$ and initiator concentration of $0.1 \mathrm{phr}$, which gave grafted material with a very low content of gel $(<5 \%)$. The NXT-grafted-NR is prepared using 10 and $20 \mathrm{phr}$ of NXT, and characterized by Fourier-transform infrared (FTIR) and proton nuclear magnetic resonance $\left({ }^{1} \mathrm{H}-\mathrm{NMR}\right)$ spectroscopic techniques, and elemental analysis by scanning electron microscopy-energy dispersive X-ray spectroscopy (SEM-EDX). This silane-grafted-NR is then used as a compatibilizer for silica-reinforced NR compounds. The non-purified silane-grafted-NR is used in a range of 5-20 phr. For comparison, compounds are produced with the pure silane in the nongrafted form, in the same amounts as contained in the grafted NR. The properties of both types of compounds and vulcanizates compatibilized with silane and silane-grafted-NR are discussed in comparison with those without any compatibilizer and with reference bis-(3-triethoxysilyl-propyl)tetrasulfide TESPT. Further, the sulfur in the silanes plays a dual role: one as part of the coupling agent to attach to the 
elastomer, the other as direct curative, causing a difference in sulfur amounts in the compounds. Therefore, this work also investigates the effect of sulfur compensation relative to the sulfur contained in the reference TESPT-containing compound in order to further improve the properties of the silica-filled NR compounds with NXT-grafted-NR as compatibilizer.

\section{Experimental}

\subsection{Materials}

Natural rubber was ribbed smoked sheet (RSS) \#3, locally produced in Thailand. 3-Octanoylthio-1-propyltriethoxysilane (NXT) (Momentive, USA) and 1,1'di(tert-butylperoxy)3,3,5-trimethylcyclohexane (Luperox $^{\circledR} 231$ XL40) (Arkema, USA) 40\% extended on calcium carbonate and silica, were used for the melt grafting reactions. The initiator and the NXT silane coupling agent details are given in Table 1. The compounding ingredients were RSS\#3, NXT, highly dispersible silica (Zeosil 1165MP, Solvay, France), bis(3-triethoxysilylpropyl)tetrasulfide (TESPT) (Evonik, Germany), treated distillate aromatic extract oil (TDAE oil) (Hansen \& Rosenthal, Germany), N-cyclohexyl-2-benzothiazole sulfenamide (CBS), diphenyl guanidine (DPG) and 2,2,4-trimethyl-1,2-dihydroquinoline (TMQ) (all from Flexys, Belgium); $\mathrm{ZnO}$, stearic acid, sulfur (all from Sigma-Aldrich Chemie, Germany).

\subsection{Preparation of silane-grafted-NR}

$\mathrm{NR}$, previously cut into small pieces, was mixed with the silane coupling agents and the initiator in an internal mixer, Brabender ${ }^{\circledR}$ 50EHT (Brabender ${ }^{\circledR} \mathrm{GmbH}$ \& Co.KG, Germany), for 12 minutes with a rotor speed of $60 \mathrm{rpm}$ using the formulations and mixing steps as shown in Table 2. The predetermined optimized grafting temperature of $140^{\circ} \mathrm{C}$ and initiator concentration of 0.1 parts per hundred rubber (phr) were used for preparing the NXT-grafted-NR by using silane amounts of 10 and $20 \mathrm{phr}$.

\subsection{Characterization of silane-grafted-NR \\ 2.3.1. Structural characterization by Fourier-transform infrared spectroscopy (FTIR) and proton nuclear magnetic resonance $\left({ }^{1} \mathrm{H}-\mathrm{NMR}\right)$ spectroscopy}

An attenuated total reflection (ATR) - FTIR spectrometer (Tensor 27, Bruker, UK) was used to characterize

Table 1. Initiator and silane coupling agent

\begin{tabular}{|c|c|c|c|}
\hline Trade names & Chemical names & Structures & $\begin{array}{c}M_{\mathrm{W}} \\
{[\mathrm{g} / \mathrm{mol}]}\end{array}$ \\
\hline Luperox $^{\circledR} 231 \mathrm{XL} 40$ & 1,1'-di(tert-butylperoxy)-3,3,5-trimethylcyclohexane & Clle & 302.4 \\
\hline NXT & 3-Octanoyl-thio-propyltriethoxysilane & $\begin{array}{c}\underset{\mathrm{CH}_{3} \mathrm{CH}_{2} \mathrm{O}}{\mathrm{CH}_{3} \mathrm{CH}_{2} \mathrm{O}-\mathrm{Si}-\left(-\mathrm{CH}_{2}\right)_{3} \mathrm{~S}-\mathrm{C}-\left(-\mathrm{CH}_{2}\right)_{6}} \mathrm{CH}_{3} \\
\underset{\mathrm{CH}_{3} \mathrm{CH}_{2} \mathrm{O}}{\mid}\end{array}$ & 365.0 \\
\hline
\end{tabular}

Table 2. Formulations and mixing procedures for preparing the silane-grafted NR

\begin{tabular}{|l|l|c|}
\hline Formulation & \multicolumn{1}{|c|}{ Chemicals } & \multicolumn{1}{|c|}{$\begin{array}{c}\text { Amount } \\
\text { [phr] }\end{array}$} \\
\hline & RSS3 & 100.0 \\
\hline & NXT & $10.0-20.0$ \\
\hline Grafting procedures & Luperox $^{\circledR} 231$ XL40 & 0.1 \\
\hline & & $\begin{array}{c}\text { Cumulative time } \\
\text { [min] }]\end{array}$ \\
\hline & NR mastication & 0 \\
\hline & Addition of NXT & 1 \\
\hline & Addition of Luperox ${ }^{\circledR} 231$ XL40 & 2 \\
\hline & Discharge & 12 \\
\hline
\end{tabular}


purified grafted NR samples. Purification of the silanegrafted NR samples was performed for the purpose of structural characterizations by dissolving the materials in toluene under continuous stirring for $72 \mathrm{~h}$, then filtering to remove any insoluble part, and subsequently precipitating the soluble part in ethanol to remove free or ungrafted silane. The purified sample was finally dried at $60^{\circ} \mathrm{C}$ for $24 \mathrm{~h}$ and kept in a desiccator before the analysis. The extent of silane grafting $(R)$ onto the NR molecules was obtained by using the peak height ratios according to Equation (1) [19]:

$$
R_{1075}=\frac{A_{1075}}{A_{1375}} \text { and } R_{1035}=\frac{A_{1035}}{A_{1375}}
$$

where $R_{1075}$ and $R_{1035}$ are the extents of silane-grafting determined at 1075 and $1035 \mathrm{~cm}^{-1}, A_{1075}$ is the peak height of Si-O-C deformation at $1075 \mathrm{~cm}^{-1}$, $A_{1035}$ is the peak height of $\mathrm{Si}-\mathrm{OSi}$ vibration and $A_{1375}$ is the peak height of $-\mathrm{CH}_{3}$ in NR at $1375 \mathrm{~cm}^{-1}$. The purified and dried grafted NR samples were dissolved in deuterated chloroform $\left(\mathrm{CDCl}_{3}\right)$ and characterized by NMR spectroscopy (Varian Unity Inova $500 \mathrm{MHz}$, Varian, USA). The amount of NXT grafted onto NR molecules in mol\% can be quantified by using Equation (2):

$\mathrm{mol} \%$ of grafted NXT on NR $=\frac{\frac{A_{3.8}}{6}}{\frac{A_{3.8}}{6}+A_{5.1}} \cdot 100$

where $A_{3.8}$ is the integrated peak area of methylene protons of the alkoxy group $\left(-\mathrm{Si}-\mathrm{O}-\mathrm{C}_{2}-\mathrm{CH}_{3}\right)$ of the NXT at $3.8 \mathrm{ppm}$, and $A_{5.1}$ is the integrated peak area of alkene protons $\left(\begin{array}{c}\mathrm{CH}_{3} \\ \stackrel{\mathrm{C}}{\mathrm{l}}=\mathrm{C} \underline{\mathrm{H}}\end{array}\right)$ of NR at $5.1 \mathrm{ppm}$.

There are 6 alkoxy-methylene protons in each NXT molecule and 1 alkene proton in each isoprene unit.

\subsubsection{Grafting efficiency of silane-grafted NR}

Based on $\mathrm{mol} \%$ of grafted silane on the NR obtained from the calculations according to Equation (2), the weight $\%$ of grafted silane can be calculated by using Equation (3):

$\mathrm{wt} \%$ of grafted silane on $\mathrm{NR}=$

$$
=\frac{\mathrm{mol} \%_{\text {silane }} \cdot M_{\mathrm{W}_{\text {silane }}}}{\mathrm{mol}_{\text {silane }} \cdot M_{W_{\text {silane }}}+\mathrm{mol}_{\mathrm{NR}} \cdot M_{\mathrm{W}_{\mathrm{NR}}}} \cdot 100
$$

where $\mathrm{mol} \%_{\text {silane }}$ is the mol\% of grafted silane on $\mathrm{NR}, M_{\mathrm{W}_{\text {silane }}}$ is the molecular weight of the silane, $\mathrm{mol} \%{ }_{\mathrm{NR}}$ is the mol\% of NR and $M_{\mathrm{W}_{\mathrm{NR}}}$ is the molecular weight of the NR repeating unit ( $68 \mathrm{~g} / \mathrm{mol})$.

Then, the grafting efficiency can be calculated according to Equation (4):

Grafting efficiency $[\%]=$

$$
=\frac{\mathrm{wt} \% \text { of grafted silane on } \mathrm{NR}}{\mathrm{wt} \% \text { of silane for the reaction }} \cdot 100
$$

\subsubsection{Elemental analysis by scanning electron microscopy-energy dispersive $\mathrm{X}$-ray spectroscopy (SEM-EDX)}

The purified silane-grafted-NR was analyzed for the chemical elements carbon $(\mathrm{C})$, oxygen $(\mathrm{O})$ and silicon $(\mathrm{Si})$ by using SEM-EDX spectroscopy (Quanta 400, FEI, USA).

\subsection{Compounds preparation}

The NXT-grafted-NR was used without purification in order to simplify the process. To study the effect of NXT-grafted-NR as a compatibilizer in silicafilled NR, the grafted-NR was added at 5,10,15 and $20 \mathrm{phr}$ as part of the rubber matrix. Total silane contents based on calculation, either in the form of free silane and of grafted silane in the compatibilizer are summarized in Table 3. The silica-filled NR compound formulations with the various amounts of NXT-grafted-NR and the straight silane, i.e. pure silane in non-grafted form, are shown in Table 4 together with the references. The compound formulations with sulfur compensation are shown in Table 5. The compounds were mixed in an internal mixer with the initial mixer temperature setting of $100^{\circ} \mathrm{C}$ to complete the silanization of silica and silane, following

Table 3. Total amount of NXT involved in NR-grafted and non-grafted forms added per phr of non-purified NXT-grafted NR, used as compatibilizer in the silica-filled NR compounds

\begin{tabular}{|c|c|}
\hline Amount of NXT-grafted-NR & $\begin{array}{c}\text { Amount of total silane } \\
{[\mathbf{w t} \% \text { rel. to silica] }}\end{array}$ \\
\hline NXT-grafted-NR with 10 phr of silane \\
\hline$\bullet 5 \mathrm{phr}$ & 0.8 \\
\hline$\bullet 10 \mathrm{phr}$ & 1.7 \\
\hline$\bullet 15 \mathrm{phr}$ & 2.5 \\
\hline$\bullet 20 \mathrm{phr}$ & 3.4 \\
\hline \multicolumn{2}{|c|}{ NXT-grafted-NR with 20 phr of silane } \\
\hline$\bullet 5 \mathrm{phr}$ & 1.5 \\
\hline$\bullet 10 \mathrm{phr}$ & 3.0 \\
\hline$\bullet 15 \mathrm{phr}$ & 4.6 \\
\hline$\bullet 20 \mathrm{phr}$ & 6.1 \\
\hline
\end{tabular}


Table 4. Compound formulations with the use of NXT-grafted-NR and straight NXT in comparison with TESPT and without any compatibilizer, without sulfur compensation

\begin{tabular}{|c|c|c|c|c|}
\hline \multirow{3}{*}{$\begin{array}{ll} & \text { Ingredients } \\
& \\
\text { RSS3 } & \end{array}$} & \multicolumn{4}{|c|}{$\begin{array}{c}\text { Parts per hundred parts of rubber } \\
{[\mathrm{phr}]}\end{array}$} \\
\hline & \multicolumn{2}{|c|}{ References } & \multirow{2}{*}{$\begin{array}{c}\text { Silane-grafted-NR } \\
95.0-80.0\end{array}$} & \multirow{2}{*}{$\begin{array}{c}\text { Straight use of silane } \\
100.0\end{array}$} \\
\hline & 100.0 & 100.0 & & \\
\hline TESPT & - & $4.7^{*}$ & - & - \\
\hline NXT-grafted-NR ${ }^{* *}$ & - & - & $5.0-20.0$ & - \\
\hline NXT & - & - & - & $0.8-6.1^{* * *}$ \\
\hline Silica & 55.0 & 55.0 & 55.0 & 55.0 \\
\hline TDAE oil & 8.0 & 8.0 & 8.0 & 8.0 \\
\hline $\mathrm{ZnO}$ & 3.0 & 3.0 & 3.0 & 3.0 \\
\hline TMQ & 1.0 & 1.0 & 1.0 & 1.0 \\
\hline Stearic acid & 1.0 & 1.0 & 1.0 & 1.0 \\
\hline DPG & 1.0 & 1.0 & 1.0 & 1.0 \\
\hline CBS & 1.5 & 1.5 & 1.5 & 1.5 \\
\hline Sulfur & 1.5 & 1.5 & 1.5 & 1.5 \\
\hline
\end{tabular}

${ }^{*}$ TESPT $4.7 \mathrm{phr}$ equals $8.6 \mathrm{wt} \%$ rel. to silica;

${ }^{* * *}$ NXT-grafted-NR was prepared by using silane contents at 10 and $20 \mathrm{phr}$;

${ }^{* * *}$ Silane contents for straight use were calculated based on silane loadings in the non-purified silane-grafted-NR as shown in Table 3.

Table 5. Compound formulations with the use of NXT-grafted-NR with sulfur compensation

\begin{tabular}{|l|c|c|c|c|c|c|c|c|}
\hline \multicolumn{1}{|c|}{ Ingredients } & \multicolumn{9}{c|}{$\begin{array}{c}\text { Parts per hundred parts of rubber } \\
\text { [phr] }\end{array}$} \\
\hline & \multicolumn{9}{|c|}{ NXT-grafted-NR with silane 10 phr } & \multicolumn{3}{c|}{ NXT-grafted-NR with silane 20 phr } \\
\hline RSS3 & 95.00 & 90.00 & 85.00 & 80.00 & 95.00 & 90.00 & 85.00 & 80.00 \\
\hline TESPT & - & - & - & - & - & - & - & - \\
\hline NXT-grafted-NR & 5.00 & 10.00 & 15.00 & 20.00 & 5.00 & 10.00 & 15.00 & 20.00 \\
\hline Silica & 55.00 & 55.00 & 55.00 & 55.00 & 55.00 & 55.00 & 55.00 & 55.00 \\
\hline TDAE oil & 8.00 & 8.00 & 8.00 & 8.00 & 8.00 & 8.00 & 8.00 & 8.00 \\
\hline ZnO & 3.00 & 3.00 & 3.00 & 3.00 & 3.00 & 3.00 & 3.00 & 3.00 \\
\hline TMQ & 1.00 & 1.00 & 1.00 & 1.00 & 1.00 & 1.00 & 1.00 & 1.00 \\
\hline Stearic acid & 1.00 & 1.00 & 1.00 & 1.00 & 1.00 & 1.00 & 1.00 & 1.00 \\
\hline DPG & 1.00 & 1.00 & 1.00 & 1.00 & 1.00 & 1.00 & 1.00 & 1.00 \\
\hline CBS & 1.50 & 1.50 & 1.50 & 1.50 & 1.50 & 1.50 & 1.50 & 1.50 \\
\hline Sulfur ${ }^{*}$ & 2.59 & 2.55 & 2.51 & 2.47 & 2.56 & 2.48 & 2.41 & 2.33 \\
\hline
\end{tabular}

${ }^{*}$ Sulfur content was compensated towards the amount of sulfur contained in TESPT in the reference compounds with $4.7 \mathrm{phr}$ TESPT in Table 4.

Table 6. Mixing procedures for compounds preparation

\begin{tabular}{|l|c|}
\hline \multicolumn{1}{|c|}{ Mixing procedures } & $\begin{array}{c}\text { Cumulative time } \\
\text { [min] }\end{array}$ \\
\hline Step 1: Internal mixer & 2 \\
\hline - NR and silane-grafted-NR (or NR only) mastication & 7 \\
\hline - Addition of first half of silica (and 1/2 of silane if any) & 12 \\
\hline - Addition of second half of silica (and 1/2 silane if any) and TDAE oil & 15 \\
\hline - Addition of ZnO, stearic acid and TMQ & \\
\hline Step 2: Two roll mill & 5 \\
\hline - Addition of DPG, CBS and sulfur(plus extra sulfur if any) & \\
\hline
\end{tabular}


the mixing procedures as shown in Table 6. The properties of the silica-filled NR compounds with the silane-grafted-NR as compatibilizer were studied in comparison with the results of silica filled NR with straight silane at different amounts.

\subsection{Measurements of Mooney viscosity, Payne effect, and bound rubber content}

Mooney viscosity $\left[\mathrm{ML}(1+4), 100^{\circ} \mathrm{C}\right]$ was tested by using a Visc $\mathrm{Tech}^{+}$(Tech-Pro Inc., USA) according to ASTM D1646. The Payne effect [22] or fillerfiller interaction of the final compounds (with curatives) was analyzed by using a Rubber Process Analyzer (RPA2000, Alpha Technologies, USA) at $100^{\circ} \mathrm{C}$, frequency $0.5 \mathrm{~Hz}$ and varying strains from 0.56 to $100 \%$. The difference of storage shear moduli at 0.56 and $100 \%$ strain was calculated and reported as the Payne effect.

For the bound rubber content determination, uncured compound (without curatives) was cut into small pieces of $0.25 \mathrm{~g}$, put into a metal cage and immersed in toluene at room temperature for $72 \mathrm{~h}$ (renewed every $24 \mathrm{~h}$ ). The sample was removed from the toluene, dried at $50^{\circ} \mathrm{C}$ for $24 \mathrm{~h}$, then immersed in toluene again for $72 \mathrm{~h}$ at room temperature in either a normal or an ammonia atmosphere. The ammonia treatment was done to cleave the physical linkages between elastomer and silica, in order to determine the chemically bound rubber versus bound rubber physical of nature. The sample was finally dried at $50^{\circ} \mathrm{C}$ for $24 \mathrm{~h}$. The bound rubber content was then calculated using the Equation (5) [23]:

Bound rubber content $[\%]=\frac{m-m_{\mathrm{S}}}{m_{\mathrm{r}}} \cdot 100$

where $m$ is the weight of sample after extraction, $m_{\mathrm{s}}$ is the weight of silica in the sample taken from the formulation and $m \llbracket$ is the original weight of rubber in the sample.

\subsection{Measurements of cure characteristics, vulcanization and tensile properties}

Cure properties of the compounds were tested by using a Moving Die Rheometer (MDR) (rheoTech $\mathrm{MD}^{+}$, Tech-Pro, Inc., USA) at $150^{\circ} \mathrm{C}$ for 30 minutes as per ASTM D 5289 at a frequency of $1.67 \mathrm{~Hz}$ and $13.95 \%$ strain. Then, the compounds were cured to their respective optimum cure times $\left(t_{\mathrm{c} 90}\right)$ at $150^{\circ} \mathrm{C}$ with a compression molding press (Chaicharoen Karnchang Ltd., Thailand). Vulcanized sheets of
$2 \mathrm{~mm}$ thickness were cut into dumbbell specimens using die type $\mathrm{C}$, and tensile testing was carried out using a Hounsfield Tensile Tester (H10KS, Hounsfield Test Equipment, England) at a crosshead speed of $500 \mathrm{~mm} / \mathrm{min}$ according to ASTM D412.

\subsection{Analysis of dynamic mechanical properties and tensile-fractured surface topography}

Storage modulus, loss modulus and $\tan \delta$ of the silica-filled NR vulcanizates containing different compatibilizers were determined using a dynamic mechanical thermal analyzer, DMTA V (Rheometrics Scientific, USA). The samples were tested in tension mode in a temperature range from -80 to $80^{\circ} \mathrm{C}$, at a frequency of $10 \mathrm{~Hz}$ under two strain deformations: $0.001 \%$ strain at -80 to $-30{ }^{\circ} \mathrm{C}$ and $0.01 \%$ strain from -30 to $80^{\circ} \mathrm{C}$.

Tensile fractured surfaces of silica-filled NR vulcanizates were analyzed by using the scanning electron microscopy (SEM) technique. The fractured surface was gold-coated before being analyzed by SEM (Quanta 400, FEI).

\section{Results and discussion}

\subsection{Grafting of NXT onto NR molecules}

Under the grafting conditions, the peroxide initiator is decomposed giving reactive radicals as shown in Figure 1, and a possible reaction mechanism of the NXT grafting onto NR molecules in the presence of radicals is shown in Figure 2. The Luperox ${ }^{\circledR} 231$ XL40 is a diperoxide initiator that can be thermally decomposed to give two free radicals or radical species $\left(\bullet \mathrm{OC}\left(\mathrm{CH}_{3}\right)_{3}\right)$ per molecule. The tert-butoxy radicals can further split to create more reactive methyl radicals $\left(\cdot \mathrm{CH}_{3}\right)$ under the high grafting temperature, as shown in Figure 1. Both types of reactive free radicals formed in the system [24] can initiate the grafting reaction on the NR which may proceed through two different pathways via $\mathrm{H}$-abstraction and addition [25], as shown in Figure 2. The reactive initiator transfers its radical to the sulfur on the coupling agent which subsequently attacks a double bond of the polymer molecule. The grafting reaction tends to proceed then through an abstraction reaction at the allylic position of the NR structure, more than through the addition reaction like with common sulfur vulcanization [26]. Upon successful grafting a covalent $\mathrm{C}-\mathrm{S}-\mathrm{C}$ bond between rubber and silane is generated with the pendant alkoxy groups. 


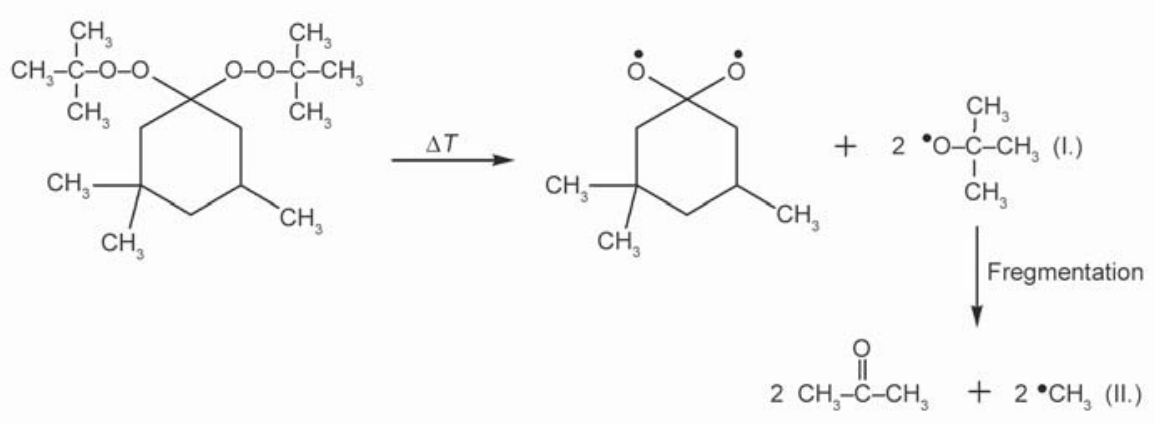

Figure 1. Decomposition of 1,1'-di(tert-butylperoxy)-3,3,5-trimethylcyclohexane (Luperox ${ }^{\circledR} 231$ XL40)
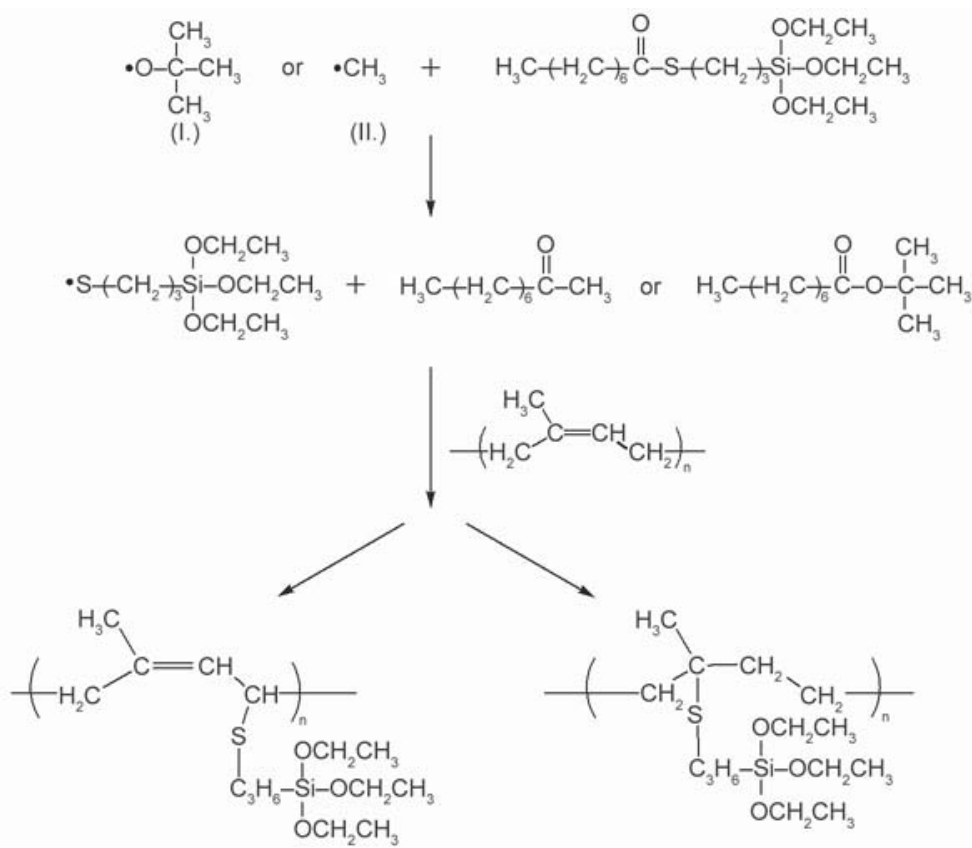

Figure 2. Postulated reaction mechanism of NXT grafting onto NR molecules in the presence of radical species

The FTIR spectra of the purified NR grafted in presence of 10 and 20 phr of NXT are shown in comparison with that of virgin NR in Figure 3. Jiao et al. [27] studied silane grafted ethylene-octene copolymer and reported that the peaks at $1167,1105,1082$ and $958 \mathrm{~cm}^{-1}$ could be assigned to the deformation of $\mathrm{Si}-\mathrm{O} \mathrm{CH}_{2} \mathrm{CH}_{3}$ of the silane coupling agent. The FTIR spectra in Figure 3 clearly show absorption bands at 1075 and $1035 \mathrm{~cm}^{-1}$ assigned to $\mathrm{Si}-\mathrm{O}-\mathrm{C}$ and $\mathrm{Si}-\mathrm{OSi}$ deformations, respectively. In this fingerprint region as seen in Figure 3, virgin NR also shows absorption bands in the range of $1400-700 \mathrm{~cm}^{-1}$, so it is not easy to identify the $\mathrm{Si}-\mathrm{O}-\mathrm{C}$ deformations of the silane grafted NR. However, the peak intensity at $1075 \mathrm{~cm}^{-1}$ relative to the neighboring peaks at 1125 and $1035 \mathrm{~cm}^{-1}$ has changed, indicating that reactions have taken place between silane and rubber. There are absorption bands at $3270 \mathrm{~cm}^{-1}$ from $\mathrm{O}-\mathrm{H}$ stretching deformations due to hydrolysis of the alkoxy-group in the silane structure during the grafting reaction or during the post-treatment; respectively at $1010 \mathrm{~cm}^{-1}$ which may be assigned to the $\mathrm{Si}-\mathrm{OH}$ group [28] due to hydrolysis of the ethoxy groups. The hydrolysis of ethoxy groups by moisture during the grafting reaction leads to hydroxyl groups $\mathrm{Si}-\mathrm{OH}$ which can further form a crosslink $\mathrm{Si}-\mathrm{O}-\mathrm{Si}$ in the grafted rubber. By taking the peak heights at 1075 and $1035 \mathrm{~cm}^{-1}$ relative to the peak at $1375 \mathrm{~cm}^{-1}$ as internal standard, the increased amount of the silane used for the grafting reactions with NR results in the increase of peak height ratios or $\mathrm{R}$ values as shown in Table 7, indicating the presence of more grafted silane fragments.

Figure 4 shows ${ }^{1} \mathrm{H}-\mathrm{NMR}$ spectra of the purified NXTgrafted-NRs prepared by using two different NXT amounts of 10 and $20 \mathrm{phr}$ in comparison with that of virgin NR. The grafted rubber shows a characteristic peak of NXT-silane at a chemical shift of $3.8 \mathrm{ppm}$ assigned to the proton of the ethoxy-groups of the silane. This peak is intensified with increasing silane amount and the mol\% of NXT-silane in the grafted NR as calculated according to Equation (2) is shown 


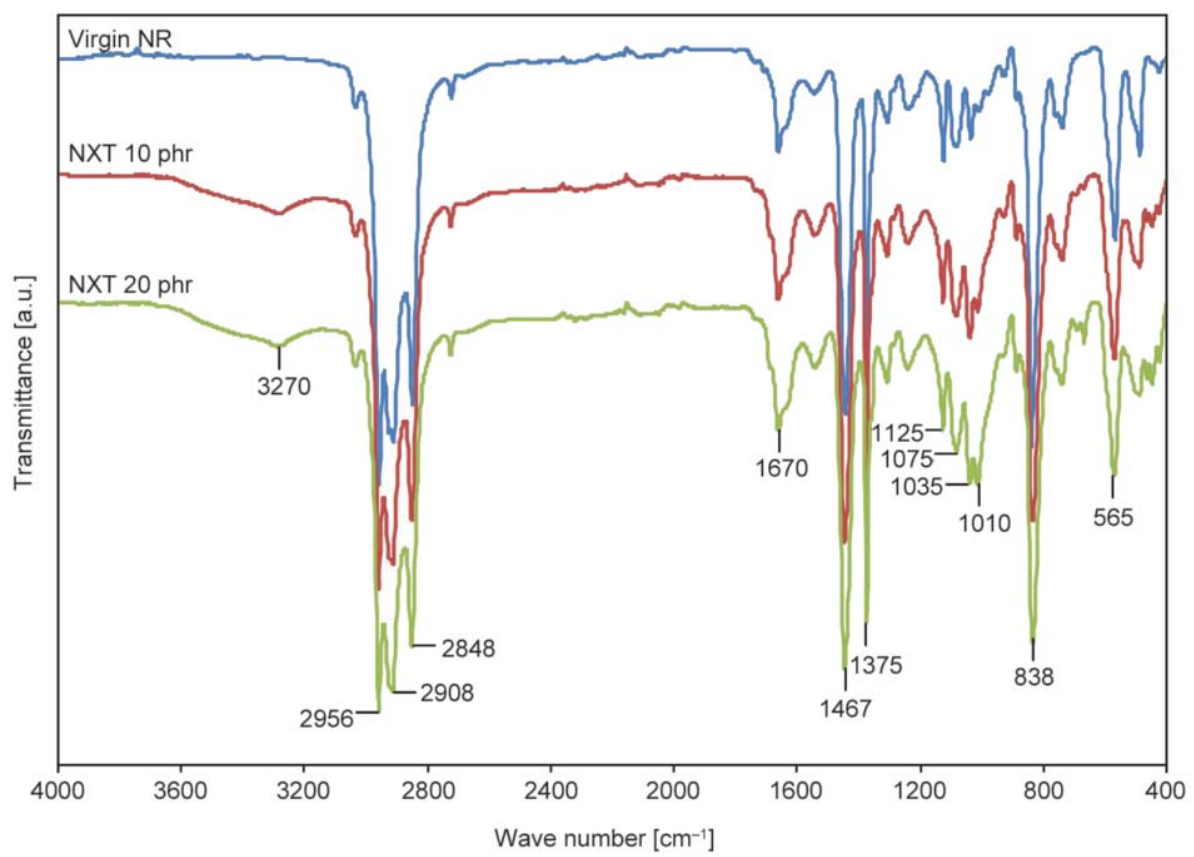

Figure 3. ATR-FTIR spectra of virgin NR and NR grafted with NXT at 10 and $20 \mathrm{phr}$

Table 7. The extent of NXT grafting $(R)$ onto NR molecules from ATR-FTIR, mol\% of NXT on NR molecules from ${ }^{1} \mathrm{H}-\mathrm{NMR}$, grafting efficiency and chemical elements from SEM-EDX

\begin{tabular}{|c|c|c|c|}
\hline \multirow[t]{2}{*}{ Analysis results } & \multicolumn{3}{|c|}{$\begin{array}{c}\text { Amount of NXT } \\
{[\mathrm{phr}]}\end{array}$} \\
\hline & 0 (virgin NR) & 10 & 20 \\
\hline \multicolumn{4}{|l|}{$R$ value from ATR-FTIR } \\
\hline$R_{1075}=A_{1075} / A_{1375}$ & 0.31 & 0.49 & 0.55 \\
\hline$R_{1035}=A_{1035} / A_{1375}$ & 0.22 & 0.42 & 0.49 \\
\hline Mol\% of NXTfrom ${ }^{1} \mathrm{H}-\mathrm{NMR}$ & 0.00 & 0.66 & 1.32 \\
\hline Amount of grafted NXT [wt $\%]$ & - & 3.43 & 6.68 \\
\hline Amount of NXT used [wt\%] & - & 9.09 & 16.67 \\
\hline Grafting efficiency [\%] & - & 37.70 & 40.10 \\
\hline \multicolumn{4}{|l|}{ Chemical elements from SEM-EDX } \\
\hline $\mathrm{C}[\mathrm{wt} \%]$ & 98.20 & 97.50 & 96.8 \\
\hline $\mathrm{O}[\mathrm{wt} \%]$ & 1.80 & 2.40 & 3.00 \\
\hline $\mathrm{Si}[\mathrm{wt} \%]$ & - & 0.10 & 0.20 \\
\hline
\end{tabular}

in Table 7. The grafted silane on the NR molecules increases with increasing amount of silane used for the reaction. The presence of the silane grafted on the NR molecules is also confirmed by elemental analysis, as reported in Table 7. The grafting of silane fragments on the NR molecules is proved by the presence of silicon atoms in the modified NR; the increase of silane content used for the reaction results in an increase of Si and $\mathrm{O}$ components in the grafted materials.

\subsection{Effect of silane-grafted-NR as} compatibilizer and of straight non-grafted silane on the properties of silica-filled NR compounds, without sulfur compensation

\subsubsection{Mooney viscosity, bound rubber content and Payne effect}

For filled rubber compounds, the viscosity increment depends on several factors, to include mastication time [29], mixing time [30], filler types [31, 32], filler contents $[32,33]$, compatibilizer or coupling 


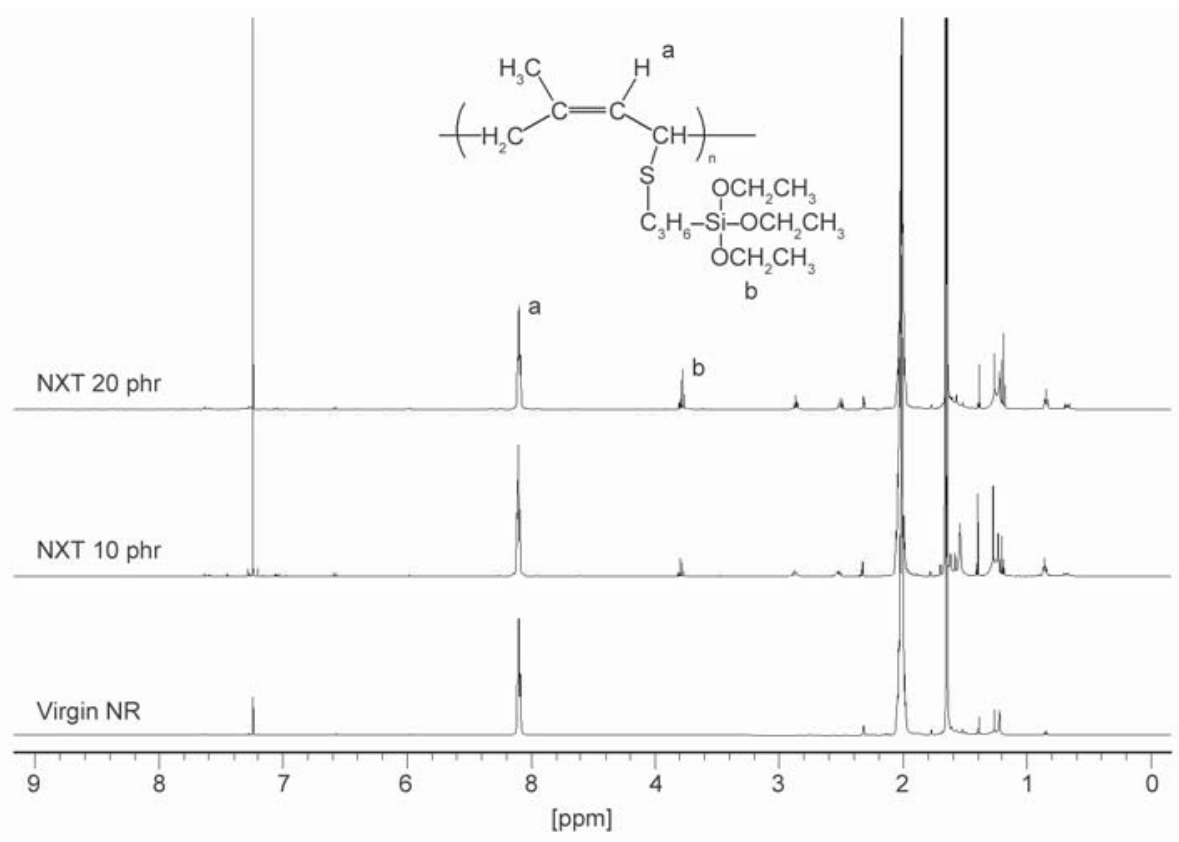

Figure 4. ${ }^{1} \mathrm{H}-\mathrm{NMR}$ spectra of virgin NR and NR grafted with NXT at 10 and $20 \mathrm{phr}$

agent $[34,35]$ and storage time [36]. The change of compound viscosity is strongly influenced by the levels of filler-filler and filler-rubber interactions which consequently have an influence on the final properties of the filled rubber. The decrease of compound viscosity results in a lower mixing torque and consequently less heat generation or lower compound temperature after mixing.

Mooney viscosities of the silica-filled NR compounds decrease with increasing amounts of silane, either in the form of NR- $g$-silane or straight nongrafted silane, and both sets of compounds show similar Mooney viscosities, as shown in Figure 5. The Mooney viscosity of the filled-NR with $6 \mathrm{wt} \%$ of silane relative to the silica, decreases to almost the same level as that of the reference compound with TESPT at $8.6 \mathrm{wt} \%$ relative to the silica. This level of $8.6 \mathrm{wt} \%$ of TESPT relative to the silica was found to be the optimum, as calculated based on the work described by Guy et al. [37]. For silica-filled compounds, the viscosity reduces when filler dispersion is improved [35]. Thus, the incorporation of NXT and NXT-grafted-NR improves the silica dispersion and consequently reduces the Mooney viscosity due to a diminished hydrophilic character of the silica after the silanization reaction. As expected, the silica-filled NR compound without any compatibilizer shows the highest Mooney viscosity because of the strong fillerfiller interactions via hydrogen bonding of the silanol groups on the silica surfaces that lead to poor dispersion and agglomerates to obstruct flow.

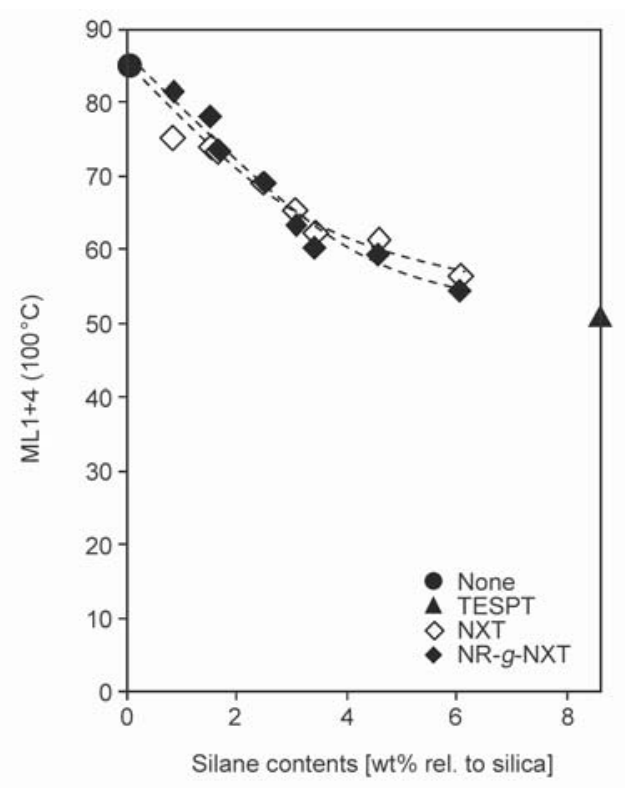

Figure 5. Mooney viscosity of silica-filled NR compounds with use of (a) straight NXT (open symbols) and NXT-grafted-NR (closed symbols)

Figure 6a shows the chemically bound rubber contents after treatment in ammonia atmosphere to cleave all weak physical filler-rubber interactions [23] of silica-filled NR compounds. The use of either silane-grafted-NR or straight non-grafted silane significantly increases the bound rubber, i.e. increased silica-rubber interaction compared to the non-compatibilized one. But the increased bound rubber content is still to a significantly lower level compared with the reference compound with TESPT. The chemically bound rubber contents increase with rising 
amount of NXT up to approx. $3 \mathrm{wt} \%$ relative to the silica, thereafter the values tend to level off. As only some of the silanol groups will react with the ethoxy groups of silane, the adsorbed silane on the silica surface will also act as a shielding agent that only forms physical interactions between filler and rubber. The chemically bound rubber content therefore reaches a saturated point, as observed in Figure 6a. The use of silane-grafted-NR tends to show a marginally higher chemically bound rubber content than the use of non-grafted silane. The partially pre-grafted silane to NR may enhance the compatibility between rubber and silica and allow the ethoxygroups of NXT to react more effectively with the silica during the silanization reaction, compared to the straight non-grafted silane. However, the use of TESPT in the silica-filled NR compound still gives an outstanding chemically bound rubber content, which is due to its tetrasulfide structure that results in premature crosslinking with the NR molecules [38] and the bis-triethoxy-groups to react with the silanol groups during silanization.

The filler-filler interaction or Payne effect of the silica-filled NR compounds with both non-grafted silane and silane-grafted-NR is remarkably decreased with increasing silane content to meet the same level of Payne effect of the compound with $8.6 \mathrm{wt} \%$ of TESPT, as shown in Figure 6b. The ethoxy-groups of the silanes undergo a silanization reaction with the silanolgroups of the silica and reduce the filler-filler interactions. The use of NXT-grafted-NR gives slightly

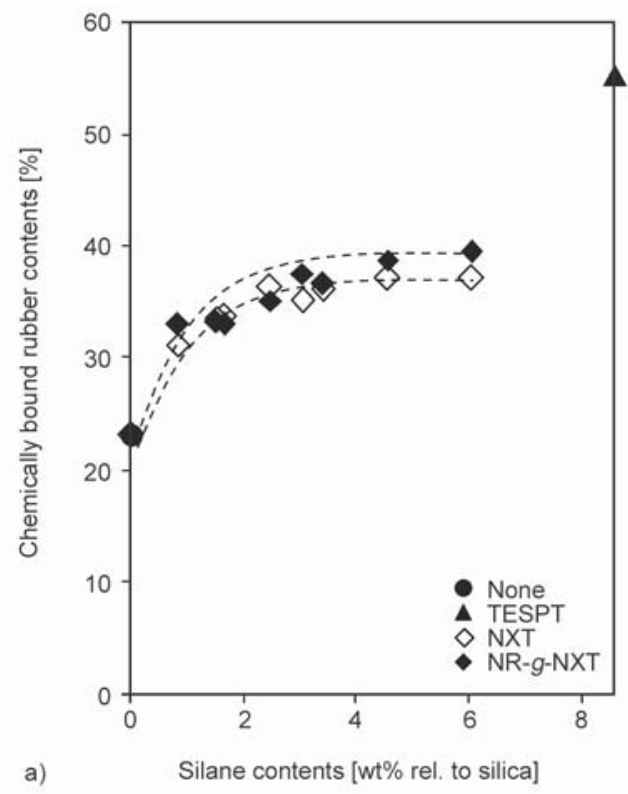

lower Payne effects than the straight use of NXT. At $6.1 \mathrm{wt} \%$ of NXT, the compound shows a slightly lower Payne effect compared to the reference compound with $8.6 \mathrm{wt} \%$ of TESPT.

\subsubsection{Tensile properties}

The modulus at $300 \%$ elongation and reinforcement index (M300/M100) of the silica filled NR vulcanizates compatibilized by straight use of silane in comparison with the use of silane-grafted-NR are shown in Figure 7. The modulus of the vulcanized silicafilled NRs significantly increases with rising silane amounts due to an increase of the silica-rubber interactions. The use of silane-grafted-NR as compatibilizer clearly gives a higher modulus than the straight use of silane. The reinforcement index of the silicafilled NR vulcanizates also increases as a function of silane content: Figure $7 \mathrm{~b}$, to reach an optimum at about $4-5 \mathrm{wt} \%$ of silane relative to the silica, above which the addition of either more non-grafted silane or silane grafted-NR results in more or less the same values. In both cases the property level of the TESPTfilled compound is not reached. The increasing fillerrubber interactions as derived from the chemically bound rubber contents: Figure $6 \mathrm{a}$, lead to a higher resistance to deformation, but because there are no additional crosslinks generated by sulfur donated to the compounds by the silane molecules like in the case of TESPT, the NXT silanized compounds therefore have a significantly lower modulus.

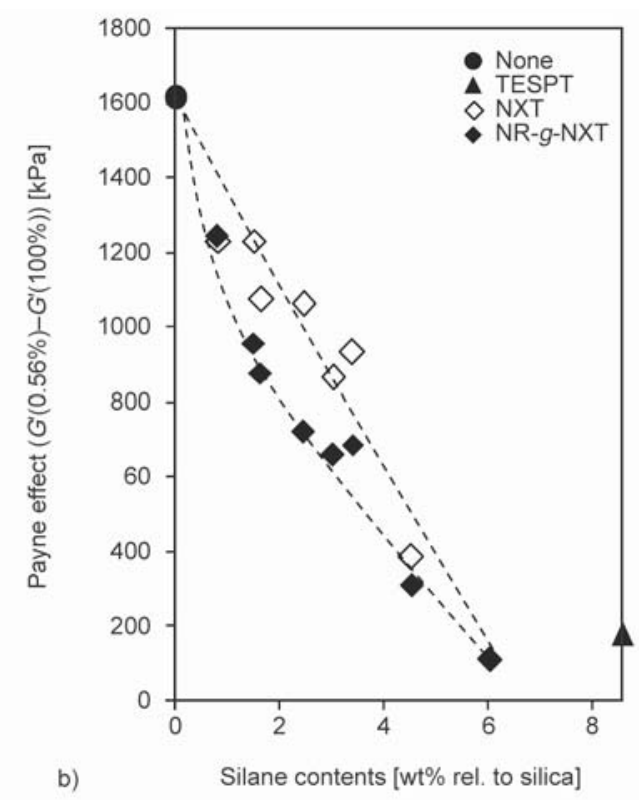

Figure 6. Chemically bound rubber contents (a) and Payne effect (b) of silica-filled NR compounds with use of (a) straight NXT (open symbols) and NXT-grafted-NR (closed symbols) 

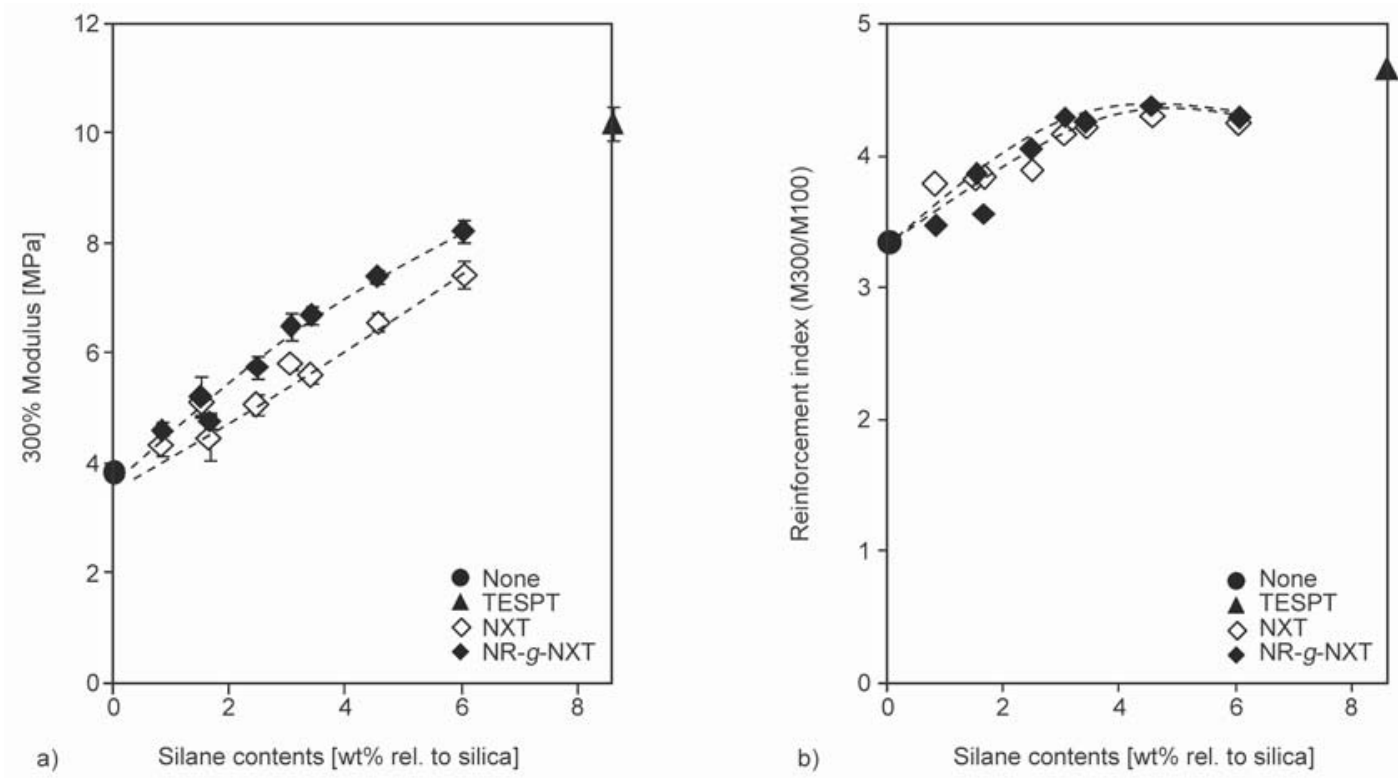

Figure 7. 300\% Modulus (a) and reinforcement index (b) of silica-filled NR compounds with use of (a) straight NXT (open symbols) and NXT-grafted-NR (closed symbols)

The tensile strength and elongation at break of the silica-filled NR vulcanizates with silane-grafted-NR and straight non-grafted silane as compatibilizers show only small differences, where the tensile strength reaches a level slightly lower than that of the vulcanizate with $8.6 \mathrm{wt} \%$ of TESPT relative to the silica: Figure 8 . The use of either straight silane or silanegrafted-NR clearly improves the tensile strength of the silica-filled NR, as a result of the increased silica-rubber interactions by the coupling reaction of the silanes. The correlations of $300 \%$ modulus and tensile strength with filler-rubber interactions as determined

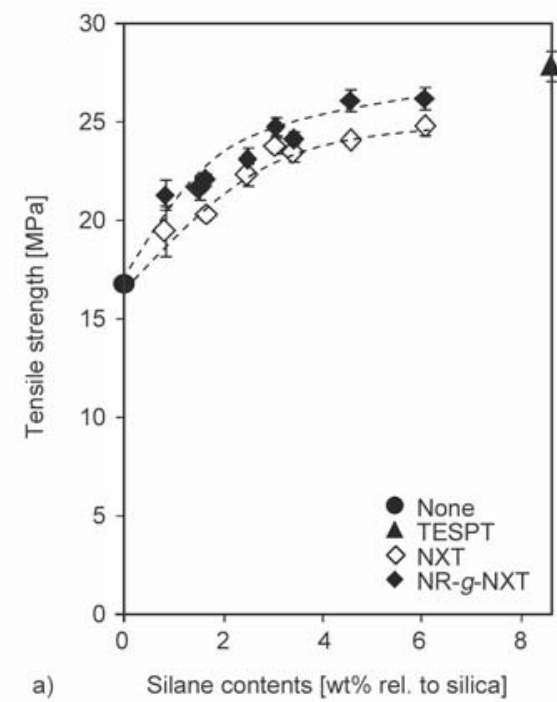

by chemically bound rubber contents are clearly demonstrated in Figures 9. Like the 300\% modulus in Figure 7a, the use of NXT-grafted-NR as compatibilizer gives a higher tensile strength than the straight use of NXT-silane, but the value is still lower than for TESPT that provides the best silica reinforcement for the NR compounds. The coupling between silica and rubber that leads to the increased modulus and tensile strength affects the elongation at break slightly, decreasing a little as shown in Figure 8b. A small reduction of elongation at break despite a large increase in modulus and tensile strength derives from

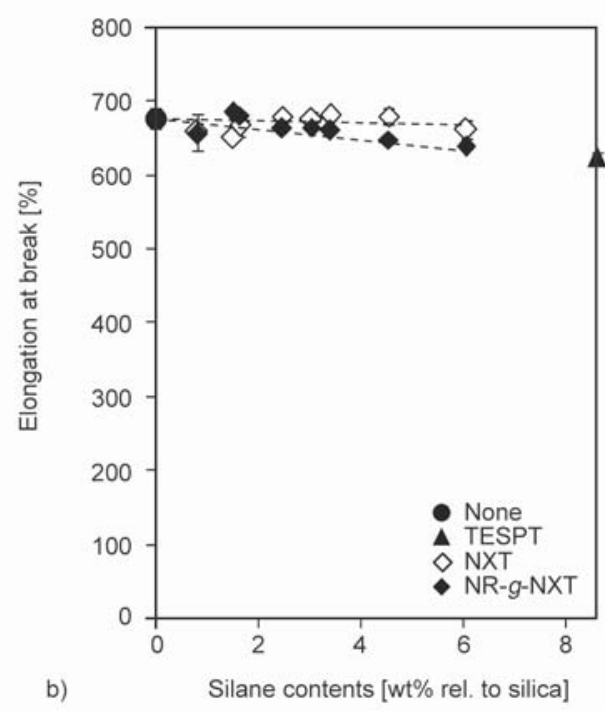

Figure 8. Tensile strength (a) and elongation at break (b) of silica-filled NR compounds with use of (a) straight NXT (open symbols) and NXT-grafted-NR (closed symbols) 

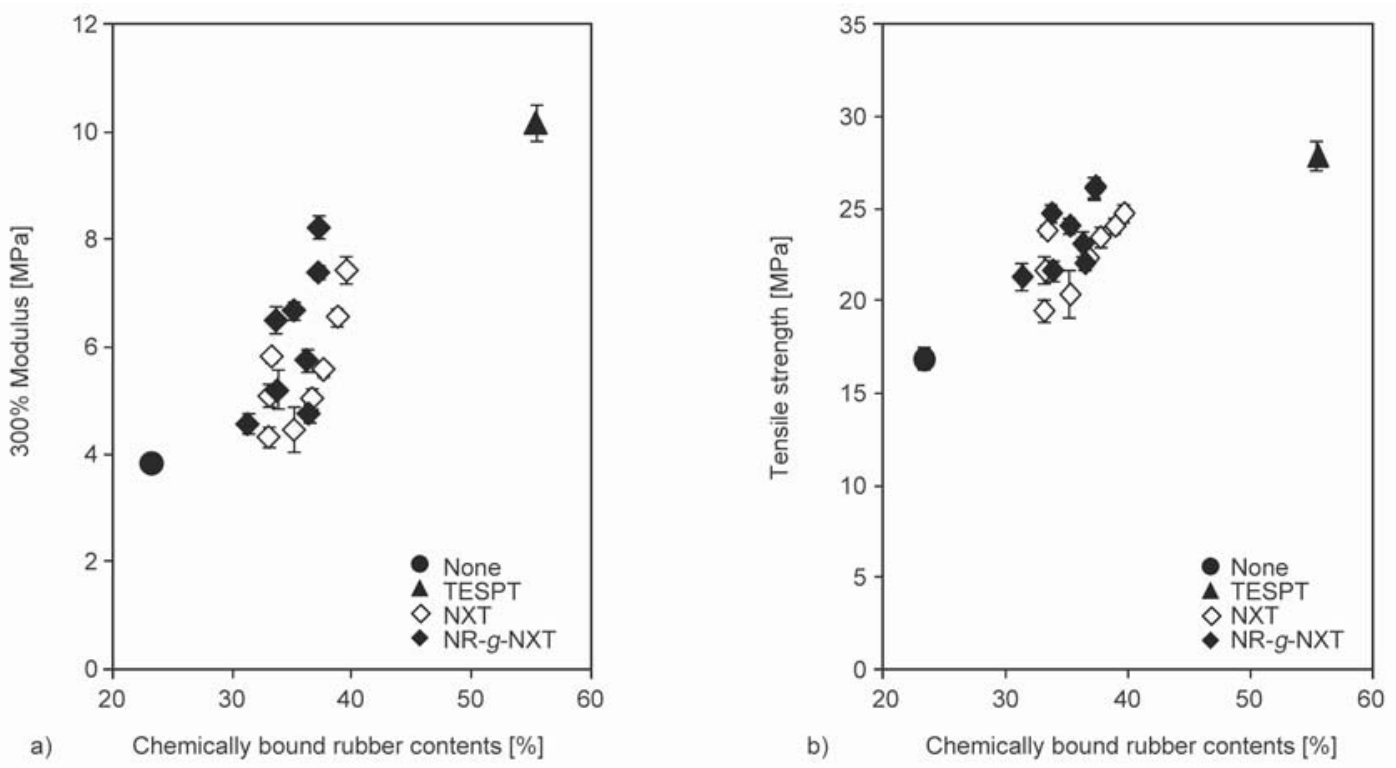

Figure 9. Correlation between 300\% modulus (a) and tensile strength (b) with chemically bound rubber content of silicafilled NR compounds

the good elasticity of natural rubber matrix. The incorporation of silane promotes interfacial adhesion between filler surface and rubber without sacrificing the toughness of the cured rubber.

\subsubsection{Dynamic mechanical properties}

The storage modulus $\left(E^{\prime}\right)$ and loss tangent or $\tan \delta$ as a function of the temperature of the silica-filled NR vulcanizates are shown in Figures 10, respectively. In the glassy region, the silica-filled vulcanizate with TESPT shows only a small difference in storage

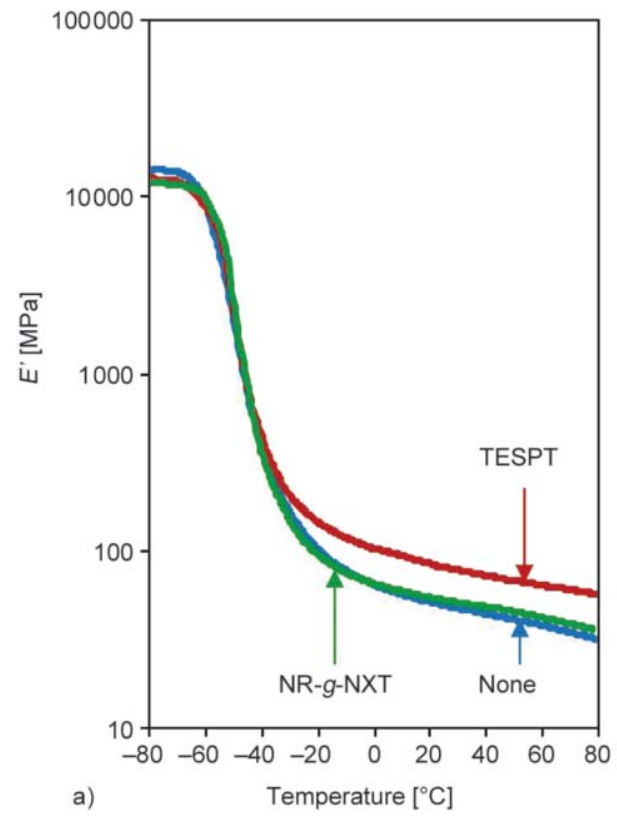

modulus compared to the mixes with NXT-graftedNR. However, in the rubbery region, the silica/TESPT system shows the highest storage modulus while the other vulcanizates show similar levels of lower moduli. For filled rubbers, the modulus depends on filler content, crosslink density, filler-filler and filler-rubber interactions that affect the segmental mobility of the rubber chains. The modulus normally increases with increasing amount of filler [39] or degree of filler-rubber interaction [40]. The silica-filled NR with TESPT has the highest storage modulus, indicative

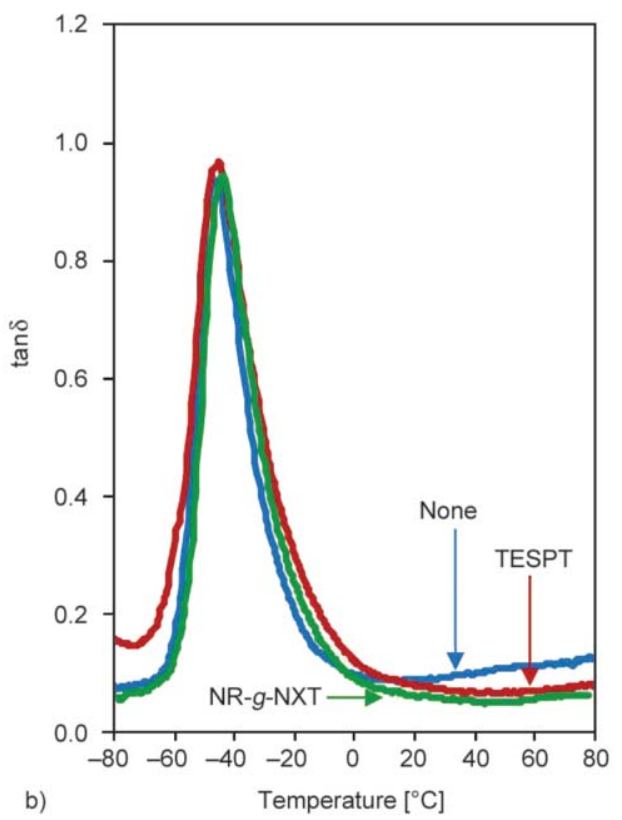

Figure 10. Storage modulus $\left(E^{\prime}\right)($ a) and loss tangent $(\tan \delta)(b)$ of silica-filled NR with NXT-grafted-NRs, both with total silane of $6.1 \mathrm{wt} \%$ relative to the silica; TESPT at $8.6 \mathrm{wt} \%$ relative to silica 
Table 8. $T_{\mathrm{g}}$ and $\tan \delta$ values of silica-filled NR vulcanizates with a total silane content of $6.1 \mathrm{wt} \%$ relative to the silica for NR-g-NXT; and $8.6 \mathrm{wt} \%$ for TESPT

\begin{tabular}{|l|c|c|c|c|}
\hline \multirow{2}{*}{\multicolumn{1}{c|}{ Compatibilizer types }} & \multicolumn{1}{c|}{$\boldsymbol{T}_{\mathbf{g}}$} & \multicolumn{3}{c|}{ Values of $\tan \boldsymbol{\delta}$} \\
\cline { 2 - 5 } & at tan $\boldsymbol{\delta}$ peak & at peak & at $\mathbf{5}^{\circ} \mathbf{C}$ & at $^{\circ} \mathbf{6 0}^{\circ} \mathbf{C}$ \\
\hline Without compatibilizer & -47 & 0.94 & 0.09 & 0.11 \\
\hline TESPT & -45 & 0.97 & 0.10 & 0.07 \\
\hline NR-g-NXT & -44 & 0.95 & 0.08 & 0.05 \\
\hline NR-g-NXT + sulfur & -42 & 0.93 & 0.08 & 0.06 \\
\hline
\end{tabular}

of most filler-rubber interactions and highest crosslink density contributed from sulfur in the TESPT molecules.

The rubber with TESPT shows a slightly higher $\tan \delta$ peak intensity over the other vulcanizates, which indicates that there is less trapped rubber in the silica network and so more flexible rubber chains to respond to the dynamic deformation in the transition region. In the rubbery region where the rubber chains are in motion, the compatibilized systems show lower $\tan \delta$ values compared to the non-compatibilized one, due to their better filler-rubber interactions and so less energy loss during deformation. The values of $\tan \delta$ at different positions are summarized in Table 8 , together with the values of $T_{\mathrm{g}}$ taken from the $\tan \delta$ peaks.

The glass transition temperature $\left(T_{\mathrm{g}}\right)$ is the temperature of the glass-to-rubber softening transition which can be observed as a large drop in modulus. Although the $T_{\mathrm{g}}$ is often taken at the peak of $\tan \delta$, the $T_{\mathrm{g}}$ of a polymer may also be reported by using the temperature at either the loss modulus $\left(E^{\prime \prime}\right)$ peak, where the value at the $E^{\prime \prime}$ peak corresponds to segmental relaxation processes only and is not affected by different levels of filler-rubber interaction [41]. This present work compares the $T_{\mathrm{g}}$ 's of the silicafilled NRs with different compatibilizers taken from the $\tan \delta$ peak, as shown in Table 8 . The $T_{\mathrm{g}}$ 's of the silica-filled vulcanizates with TESPT and NXTgrafted-NR are shifted to a higher temperature compared to the one without compatibilizer, due to an increased degree of filler-rubber interactions which restrict the mobility of the polymer chains. Although the compounds with NXT-grafted-NR as compatibilizer show lower chemically bound rubber content and inferior mechanical properties than for TESPT, their $T_{\mathrm{g}}$ 's are slightly higher than the one with TESPT. The use of silane grafted-NR with some silane molecules already grafted to rubber may result in a higher extent of the coupling reaction between rubber and silica. In the transition region, the free volume between polymer molecules rapidly increases leading to an increase of polymer chain mobility to respond to dynamic deformation. The better chain flexibility in the compatibilized compounds and good filler-rubber interactions lead to lower energy losses and so lower $\tan \delta$ in the rubbery region.

The $\tan \delta$ values at low temperature, i.e. $5-35^{\circ} \mathrm{C}$ for summer tires and $2-20^{\circ} \mathrm{C}$ for winter tires [42], and at higher temperatures commonly at $60^{\circ} \mathrm{C}$ can be used to indicate tire wet grip and rolling resistance, respectively. The results in Table 8 shows that the use of NXT-grafted-NR as compatibilizer gives slightly lower $\tan \delta$ values at $5{ }^{\circ} \mathrm{C}$, indicating a small decrease in wet grip, respectively a lower $\tan \delta$ at $60^{\circ} \mathrm{C}$ implying an improvement in rolling resistance compared to the reference compound with TESPT. The lower $\tan \delta$ at $60^{\circ} \mathrm{C}$ in the vulcanizates containing the silane-grafted-NR again may be attributed to efficient coupling or bridging between rubber and silica via the pre-grafted silane fragments and some additional linkages created by self-crosslinking between the grafted moieties.

\subsubsection{SEM micrographs}

SEM micrographs of tensile fractured surfaces of silica-filled NR vulcanizates without compatibilizer, with TESPT, with non-grafted NXT and with NXTgrafted-NR are compared in Figures 11. A smooth failure surface of a silica-filled vulcanizate is due to a weak filler-rubber interaction and poor silica dispersion, whereas a rough failure surface with many tear lines from ductile failure indicates a good silica-rubber interaction and high tensile strength [ 43 , 44]. The SEM micrographs of the vulcanizates with no compatibilizer and with reference TESPT, as shown in Figure 11a and $11 \mathrm{~b}$ respectively, clearly correspond to their different tensile strengths: Figure $8 \mathrm{a}$. The addition of NXT silane, both in pure silane form and NXTgrafted-NR, improves the silica-rubber 


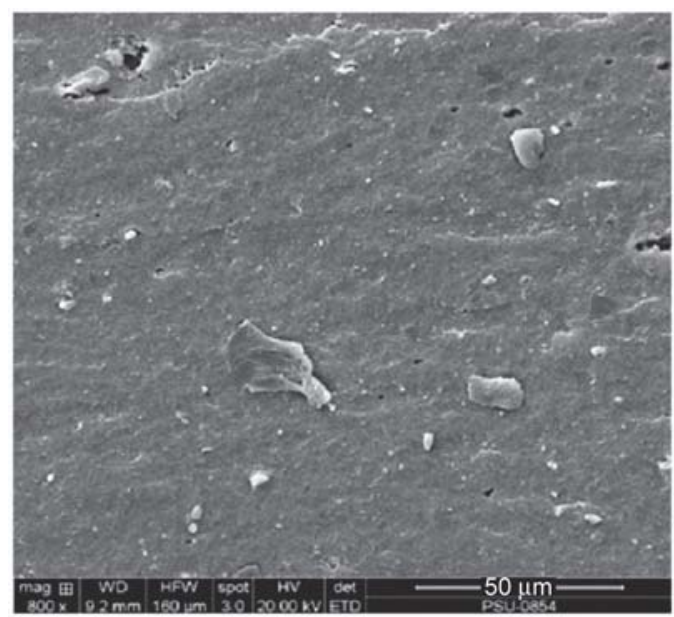

a)

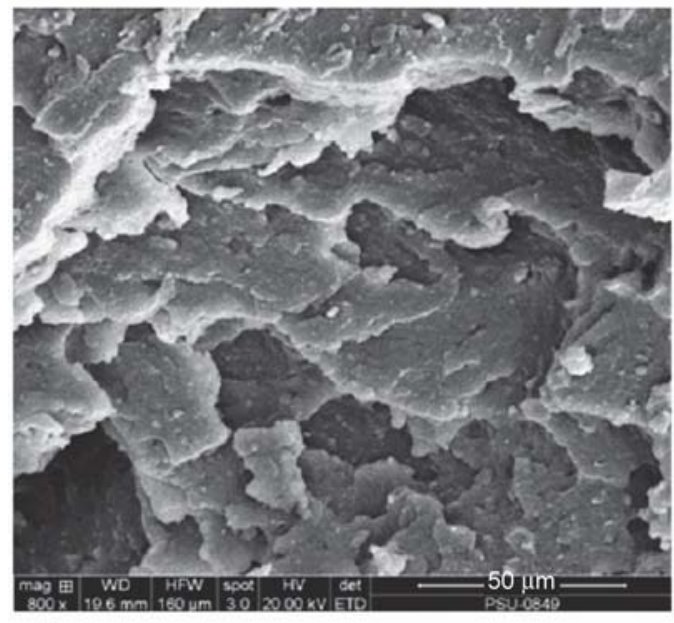

c)

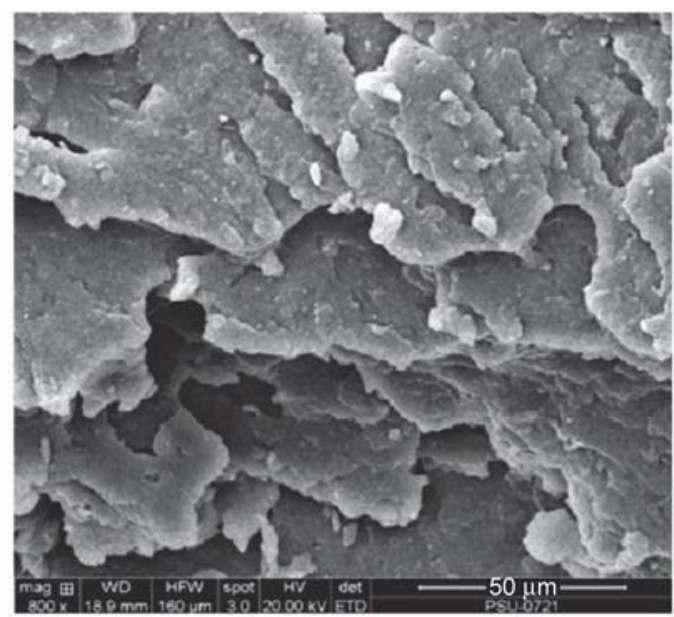

b)

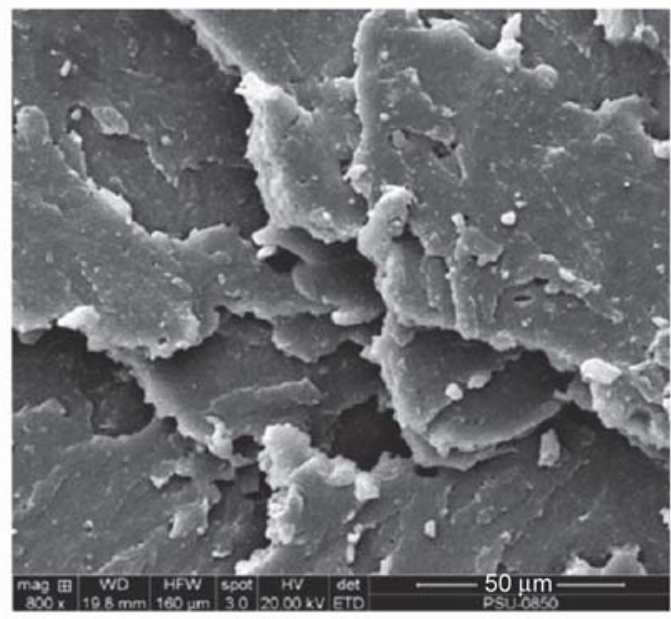

d)

Figure 11. SEM micrographs of tensile fractured surfaces of silica-filled NR vulcanizates at $800 \times$ magnification: (a) without compatibilizer; (b) with TESPT at $8.6 \mathrm{wt} \%$ rel. to silica; (c) with NXT at $6.1 \mathrm{wt} \%$ rel. to silica; and (d) with NXTgrafted-NR containing total NXT of $6.1 \mathrm{wt} \%$ rel. to silica

interactions to lead to more surface roughness and tear lines on the failure surfaces when compared to the filled vulcanizate without compatibilizer, and the surface topography resembles more that of the reference compound with TESPT. However, there is no clear difference in the failure surface patterns of the filled vulcanizates prepared by the straight use of silane and by the use of silane-grafted-NR.

\subsection{Effect of silane-grafted-NR as} compatibilizer with sulfur compensation on the properties of silica-filled NR compounds

Some previous studies reported the influence of sulfur content in the silica-reinforced rubber compounds, such as ten Brinke et al. [45] who showed that, with sulfur correction, all sulfur containing silanes behaved more like TESPT; such as bis-(3-triethoxysilylpropyl)disulfide (TESPD) with sulfur correction could give final properties similar to those of TESPT. The correction of sulfur deficiency in silica-filled NR compared to the TESPT-based system also leads to enhanced properties which are related to extra network formation [46]. Therefore, the sulfur compensation relative to the sulfur contained in the reference TESPT compound was also applied in this part to improve the properties of the silica-filled NR compounds with NXT-grafted-NR as compatibilizer.

\subsubsection{Mooney viscosity, Payne effect and cure properties}

The Mooney viscosities of the silica-filled NR compounds with NXT-grafted-NR as compatibilizer with sulfur compensation show slightly lower viscosities than the non-sulfurcompensated ones, as shown in Figure 12a. The change of Mooney viscosities is mainly affected by the amounts of NXT-silane in the grafted-NR, and the compounds containing NR-g-NXT 

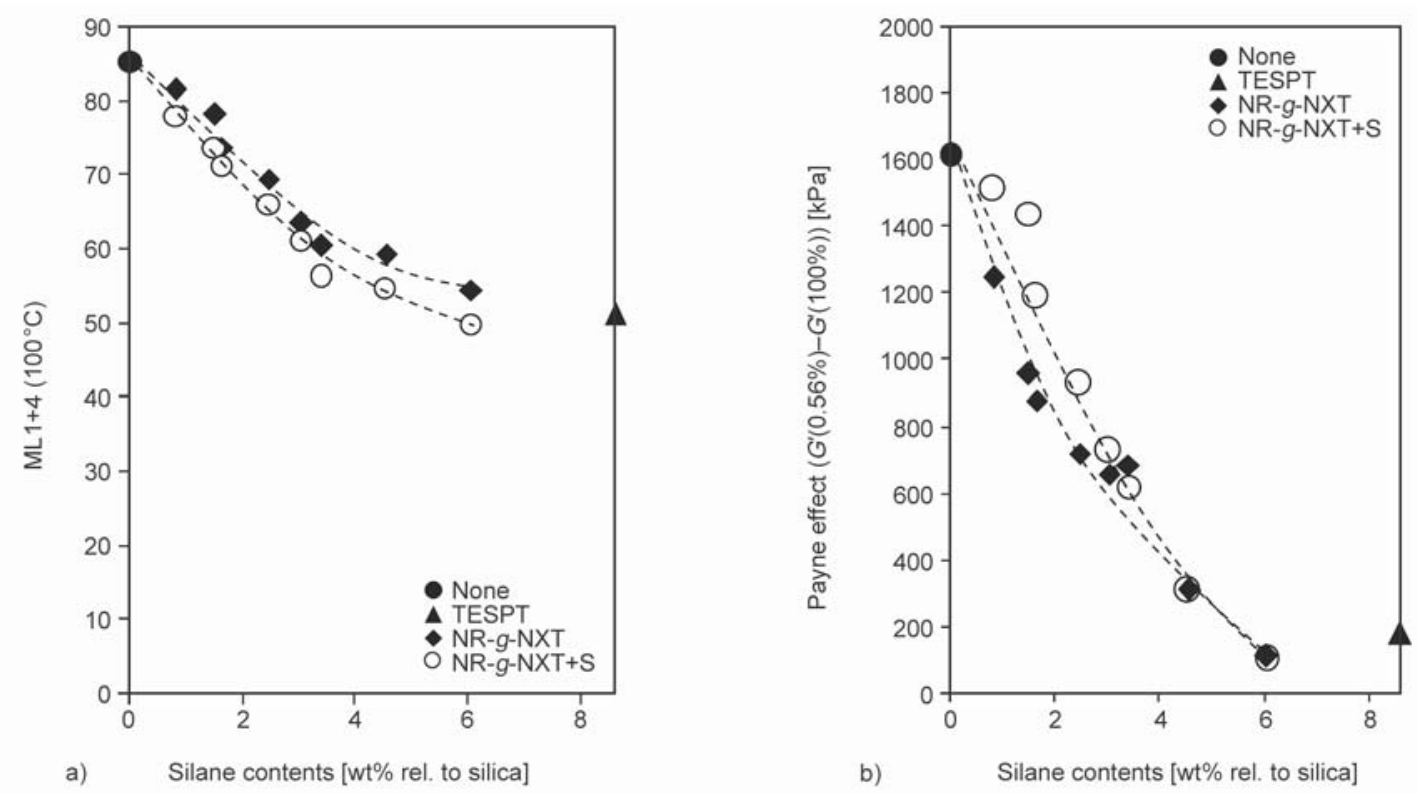

Figure 12. Mooney viscosity (a) and Payne effect (b) of silica-filled NR compounds with NXT-grafted-NR as compatibilizer without and with sulfur compensation, in comparison with the reference compounds with TESPT and without compatibilizer

at $6.1 \mathrm{wt} \%$ silane relative to the silica show more or less the same level of the Mooney viscosity to that of the reference compound. Also, the Payne effect of the silica-filled NR compounds without and with sulfur compensation shows no significant difference, as shown in Figure 12b. The Payne effect dramatically decreases with the addition of NXT-grafted-NR as compatibilizer and the silica-filled compounds with NXT 4-6 wt\% relative to the silica show similar level of the Payne effect to the reference one with $8.6 \mathrm{wt} \%$ TESPT.

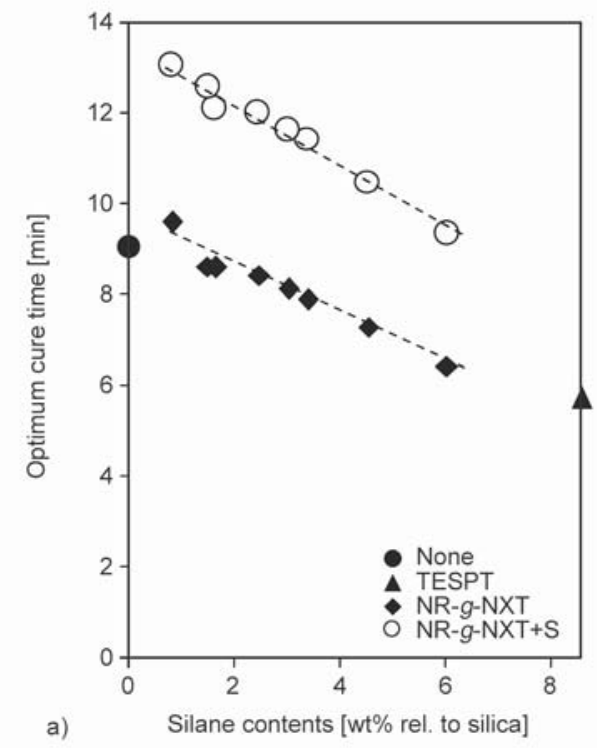

In Figure 13a, the silica-filled NR-compound with TESPT shows the shortest optimum cure time as the silane has efficiently reacted with the silanol groups on the silica surface, leading to more hydrophobicity and less curative adsoption on the silica surface. Moreover, TESPT is a sulfur donor [47]. The TESPTcompound therefore has a faster cure time compared to the other compounds. The optimum cure times of the silica-filled NR compounds with NXT graftedNR as compatibilizer decrease with increasing NXT amounts due to more reactive ethoxy-groups available

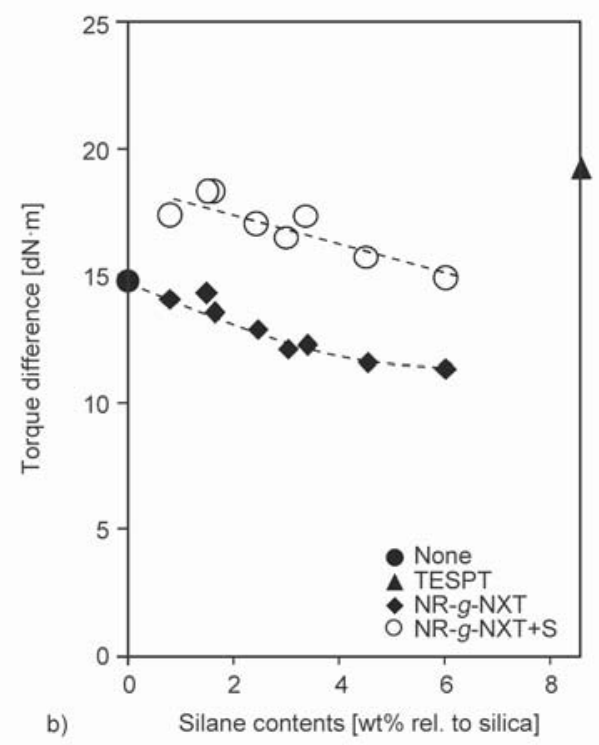

Figure 13. Optimum cure time (a) and torque difference (b) of silica-filled NR compounds with NXT-grafted-NR as compatibilizer without and with sulfur compensation, in comparison with the reference compounds with TESPT and without compatibilizer 

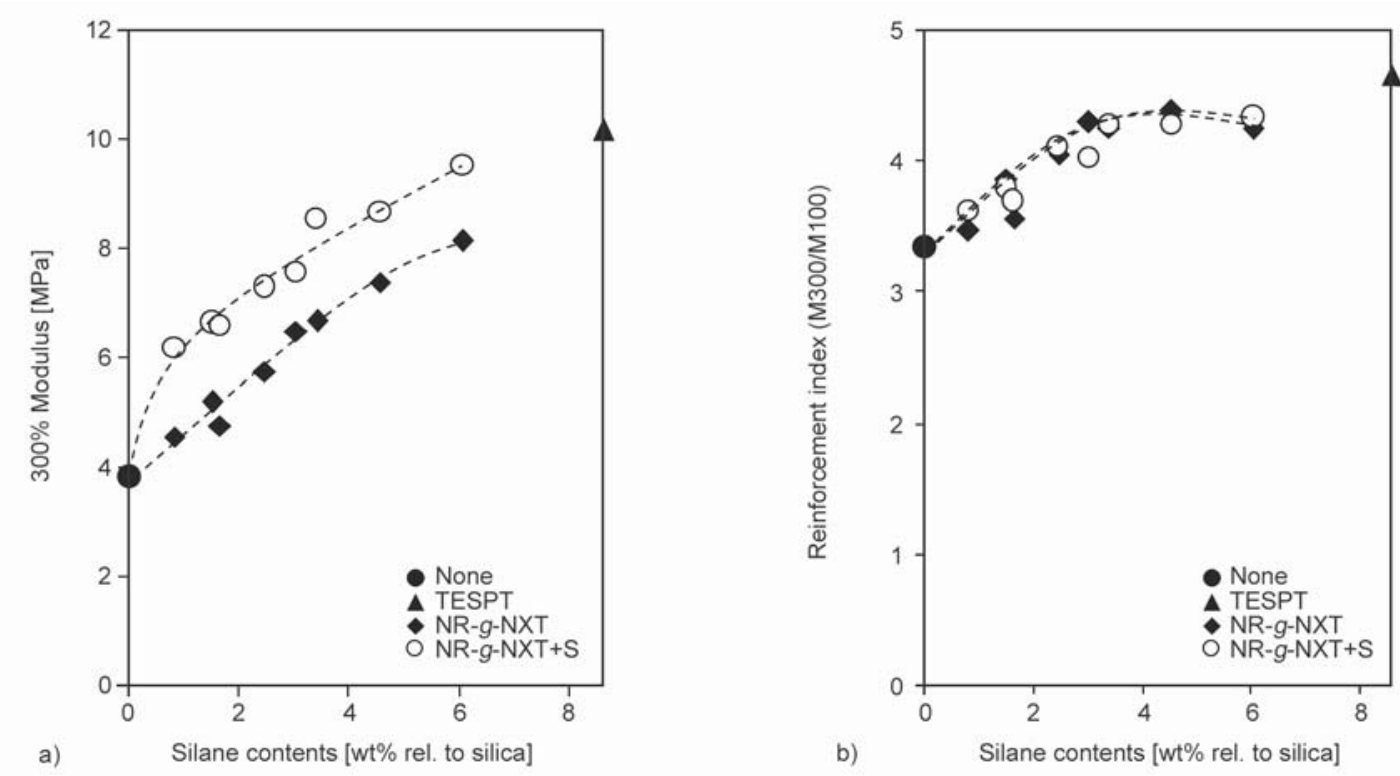

Figure 14. Modulus at 300\% elongation (a) and reinforcement index (b) of silica-filled NR compounds with NXT-graftedNR as compatibilizer without and with sulfur compensation, in comparison with the reference compounds with TESPT and without compatibilizer

to react with the silanol groups resulting in less interference with the curatives in the vulcanization reaction. The addition of more elemental sulfur to correct the total sulfur content towards the sulfur contained in the TESPT compound results in longer cure times, indicating that the change of sulfur-toaccelerator ratio has an influence on the crosslinking reaction in the rubber. In this case, the increase of sulfur content, while the accelerator and activator contents remain the same, leads to a longer time required to complete the vulcanization reaction.

The silica-filled NR-compounds with NXT-graftedNR as compatibilizer show a decrease of torque difference with increasing amounts of NXT-silane which might be caused by the presence of NXT-fragments that can act as a plasticizer. The compounds with sulfur correction show a higher torque difference compared to the compounds with non-adjusted sulfur content, as seen in Figure 13b, due to the increased crosslink density in the rubber matrix.

\subsubsection{Tensile and dynamic mechanical properties}

The $300 \%$ modulus, reinforcement index and tensile strength of the silica-filled NR vulcanizates with NXT-grafted-NR as compatibilizer, with and without sulfur correction, increase with rising silane contents as shown in Figures 14 and 15a, respectively. Sulfur compensation increases the modulus of the vulcanizates due to an increase of the crosslink density via sulfur crosslinks as indicated by the increase of torque difference in Figure 13b. However, the sulfur correction in the NXT-grafted-NR compatibilized vulcanizates has no effect on the reinforcement index, as seen in Figure 14b. The decrease in torque difference with increasing NXT-grafted-NR contents in Figure 13b does not reflect in the 300\% modulus, as would have been expected: on the contrary, the $300 \%$ modulus increases, as does the reinforcement index. The ultimate $300 \%$ modulus and reinforcement index for the sulfur compensated compounds almost reach the level obtained for straight TESPT. The presence of $4.6 \mathrm{wt} \%$ NXT relative to the silica in the NXT-grafted-NR used as compatibilizer combined with sulfur correction increases the tensile strength to the same level as that for the optimum TESPT content. With sulfur correction and increasing NXT content, the elongation at break of the vulcanizates, as shown in Figure 15b, tends to decrease slightly as a result of more filler-rubber interactions and a higher crosslink density.

Storage modulus $\left(E^{\prime}\right)$ and $\tan \delta$ of the silica-filled NR with NXT-grafted-NR, with and without sulfur correction, with TESPT and without compatibilizer are compared in Figures 16. In the glassy state, all the filled vulcanizates show a similar level of $E^{\prime}$ even though they have different degrees of filler-rubber interaction as reflected in the bound rubber contents in Figure 6a, but in the rubbery region, the sulfur compensation slightly increases the storage modulus of 

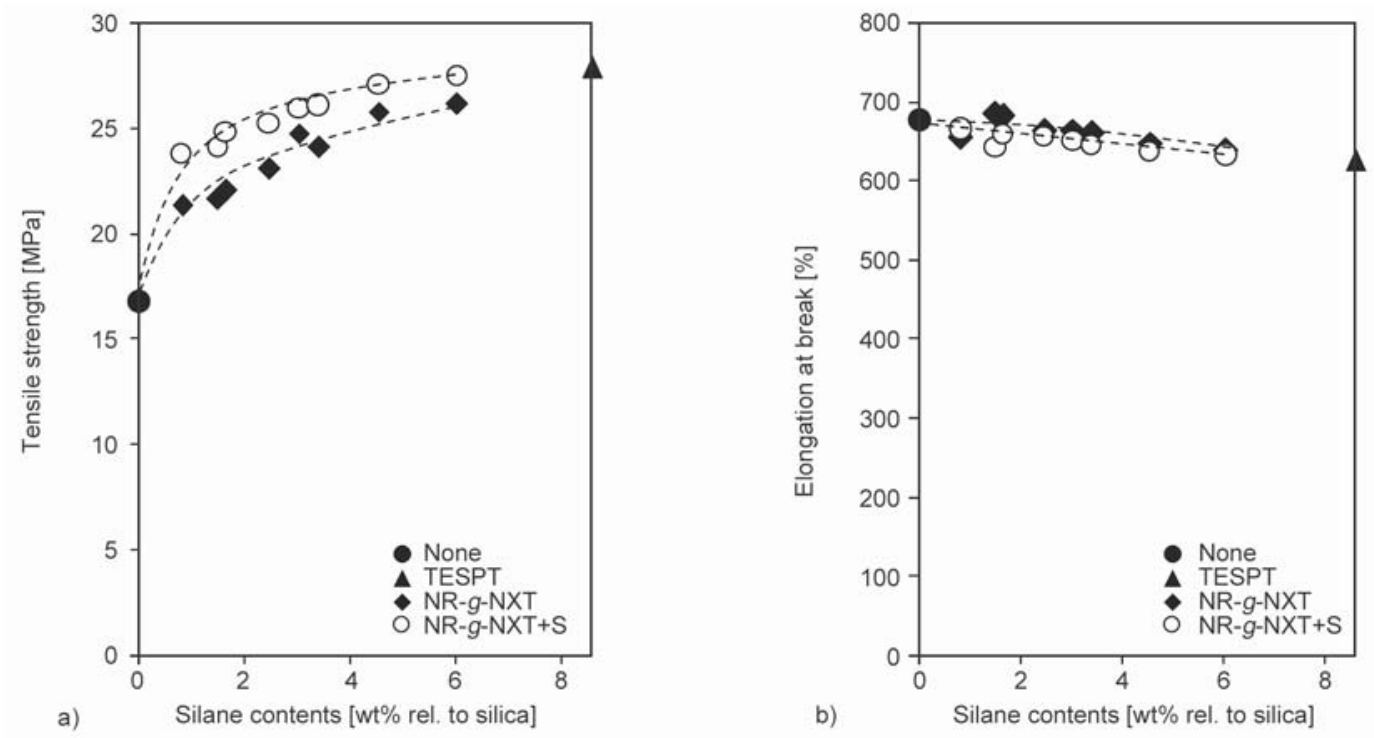

Figure 15. ensile strength (a) and elongation at break (b) of silica-filled NR compounds with NXT-grafted-NR as compatibilizer without and with sulfur compensation, in comparison with the reference compounds with TESPT and without compatibilizer

the silica-filled NR vulcanizate due to the increase of crosslink density: Figure 13b. The $\tan \delta$ peak of the silica-filled NR with NXT-grafted-NR is slightly shifted to a higher temperature compared to the silicafilled NR with TESPT and without compatibilizer, respectively. The increase of sulfur content due to the sulfur compensation towards to the level for TESPT compound results in a slight further shift of the $\tan \delta$ peak due to the increase of crosslink density, which restricts the segmental motion of the rubber chains. The $\tan \delta$ value at peak is also reduced after

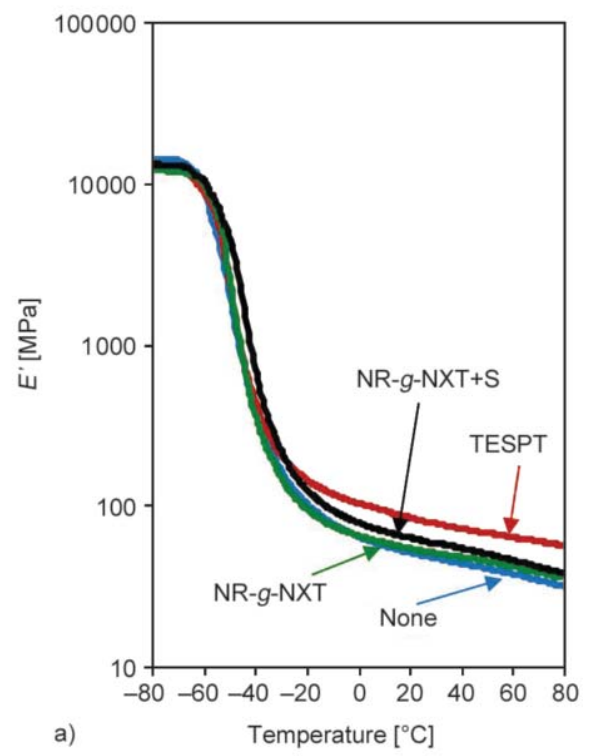

the sulfur compensation, as more crosslink points restrict the relaxation and reduce chain flexibility. The $\tan \delta$ values at different temperatures are summarized in Table 8. The use of TESPT in the silica-filled NR vulcanizate gives the highest $\tan \delta$ at $5^{\circ} \mathrm{C}$, that suggests the best wet grip for a tire-tread made thereof; and significantly lower $\tan \delta$ at $60^{\circ} \mathrm{C}$ compared to the non-compatibilized vulcanizate, indicative for rolling resistance of tire treads. However, the $\tan \delta$ at $60^{\circ} \mathrm{C}$ of the silica/TESPT system is slightly higher when compared to the vulcanizate containing NR-g-NXT.

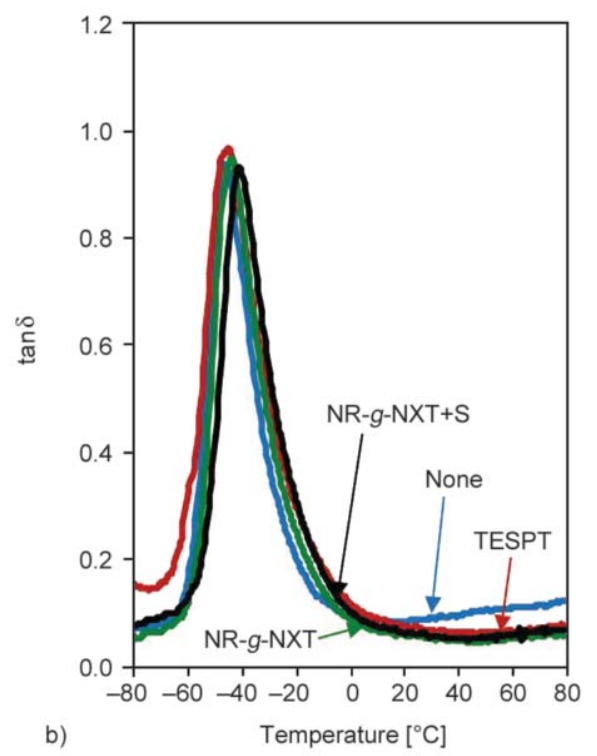

Figure 16. Storage modulus (a) and $\tan \delta$ (b) of silica-filled NR compounds with NXT-grafted-NR as compatibilizer without and with sulfur compensation, in comparison with the reference compounds with TESPT and without compatibilizer 
The use of NR-g-NXT as compatibilizer suggests therefore somewhat inferior tire wet grip compared to the use of TESPT, but the lowest $\tan \delta$ values at $60^{\circ} \mathrm{C}$ imply the lowest tire rolling resistance. The inclusion of sulfur compensation relative to the reference compound with TESPT has practically no influence on $\tan \delta$ at both 5 and $60^{\circ} \mathrm{C}$.

\section{Conclusions}

NXT-grafted-NR is successfully prepared under melt mixing conditions in an internal mixer at $140^{\circ} \mathrm{C}$ using $0.1 \mathrm{phr}$ of 1,1'-di(tert-butylperoxy)-3,3,5-trimethylcyclohexane (Luperox ${ }^{\circledR} 231$ XL40) as initiator. The NXT-grafted NR is confirmed by FTIR infrared absorption bands at 3270,1075 and $1035 \mathrm{~cm}^{-1}$ which can be assigned to the deformations of $\mathrm{OH}$, $\mathrm{Si}-\mathrm{O}-\mathrm{C}$ and $\mathrm{Si}-\mathrm{O}-\mathrm{Si}$, respectively; by $1 \mathrm{H}$ NMR as indicated by the presence of methylene protons of the alkoxy groups $\left(-\mathrm{OCH}_{2}-\mathrm{C}-\right)$ from the fragment of the silane that were attached to the NR molecule; and by elemental analysis via the SEM-EDX technique as indicated by the amounts of oxygen and silicon in the grafted NR.

Increasing amounts of NXT-grafted-NR as compatibilizer in silica-filled NR compounds decrease the Mooney viscosity, Payne effect, and increase the chemically bound rubber contents, $300 \%$ modulus, reinforcement index and tensile strength. Tensile fractured surfaces of the silica-filled NR vulcanizates indicate ductile failure with surface roughness and many tear lines when the NXT-grafted-NR is used, similar to the compound with TESPT. At the same silane loading, the use of NXT-grafted-NR as compatibilizer gives a better improvement in Payne effect, chemically bound rubber content, $300 \%$ modulus and tensile strength compared to the straight use of nongrafted silane, but the properties are still somewhat lower than for the use of TESPT at its optimum content, i.e. at $8.6 \mathrm{wt} \%$ relative to the silica. The sulfurcompensated-compounds with the NXT-grafted-NR of about $6 \mathrm{wt} \%$ NXT relative to the silica show a significantly higher cure torque difference compared to the counterparts without sulfur compensation that leads to the increase of the modulus and tensile strength of the vulcanizates to reach the level obtained for straight TESPT.

\section{Acknowledgements}

The authors gratefully acknowledge the financial support from the Dutch Natural Rubber Foundation (Rubber Stichting) and Graduate School of Prince of Songkla University.

\section{References}

[1] Zhuravlev L. T.: The surface chemistry of amorphous silica. Zhuravlev model. Colloids and Surfaces A: Physicochemical and Engineering Aspects, 173, 1-38 (2000). https://doi.org/10.1016/S0927-7757(00)00556-2

[2] Hunsche A., Görl U., Koban H. G., Lehmann T.: Investigations on the reaction silica/organosilane and organosilane/polymer: Part 2: Kinetic aspects of the silica Organosilane reaction. Kautschuk Gummi Kunststoffe, 51, 525-533 (1998).

[3] Reuvekamp L. A. E. M., ten Brinke J. W., van Swaaij P. J., Noordermeer J. W. M.: Effects of time and temperature on the reaction of TESPT silane coupling agent during mixing with silica filler and tire rubber. Rubber Chemistry and Technology,75, 187-198 (2002). https://doi.org/10.5254/1.3544972

[4] Kaewsakul W., Sahakaro K., Dierkes W. K., Noordermeer J. W. M.: Optimization of mixing conditions for silica-reinforced natural rubber tire tread compounds. Rubber Chemistry and Technology, 85, 277-294 (2012). https://doi.org/10.5254/rct.12.88935

[5] ten Brinke J. W., Debnath S. C., Reuvekamp L. A. E. M., Noordermeer J. W. M.: Mechanistic aspects of the role of coupling agents in silica-rubber composites. Composites Science and Technology, 63, 1165-1174 (2003). https://doi.org/10.1016/S0266-3538(03)00077-0

[6] ten Brinke J. W., van Swaaij P. J., Reuvekamp L. A. E. M., Noordermeer J. W. M.: The influence of silane sulfur rank on processing of a silica reinforced tire tread compound. Kautschuk Gummi Kunststoffe, 55, 244 254 (2002).

[7] Jesionowski T., Krysztafkiewicz A.: Influence of silane coupling agents on surface properties of precipitated silicas. Applied Surface Science, 172, 18-32 (2001). https://doi.org/10.1016/S0169-4332(00)00828-X

[8] Lee C. H., Park S. H., Chung W., Kim J. Y., Kim S. H.: Preparation and characterization of surface modified silica nanoparticles with organo-silane compounds. Colloids and Surfaces A: Physicochemical and Engineering Aspects, 384, 318-322 (2011).

https://doi.org/10.1016/j.colsurfa.2011.04.010

[9] Kitiyanan B., O’Haver J. H., Harwell J. H., Osuwan S.: Absolubilization of styrene and isoprene in cetyltrimethylammonium bromide admicelle on precipitated silica. Langmuir, 12, 2162-2168 (1996). https://doi.org/10.1021/la950783f

[10] Waddell W. H., O’Haver J. H., Evans L. R., Harwell J. H.: Organic polymer-surface modified precipitated silica. Journal of Applied Polymer Science, 55, 1627-1641 (1995). https://doi.org/10.1002/app.1995.070551203 
[11] Thammathadanukul V., O'Haver J. H., Harwell J. H., Osuwan S., Na-Ranong N., Waddell W. H.: Comparison of rubber reinforcement using various surface-modified precipitated silicas. Journal of Applied Polymer Science, 59, 1741-1750 (1996).

https://doi.org/10.1002/(SICI)10974628(19960314)59:11<1741::AID-APP10>3.0.CO;2-X

[12] Jain S., Goossens J. G. P., van Duin M.: Synthesis, characterization and properties of (vinyl triethoxy silanegrafted PP)/silica nanocomposites. Macromolecular Symposia, 233, 225-234 (2006). https://doi.org/10.1002/masy.200690022

[13] Yin C., Zhang Q., Gu J., Zheng J., Gong G., Liang T., Zhang H.: In situ silica reinforcement of vinyltriethoxysilane-grafted styrene-butadiene rubber by sol-gel process. Journal of Applied Polymer Science, 128, 22622268 (2013). https://doi.org/10.1002/app.38105

[14] Yin C., Zhang Q., Yin D., Gu J., Gu G., Gong G., Liang T.: Studies on preparation and properties of vinyltriethoxysilane-grafted styrene-butadiene rubber. Journal of Applied Polymer Science, 119, 2808-2814 (2011). https://doi.org/10.1002/app.33073

[15] Colucci G., Di Gianni A., Bongiovanni R., Priola A., Torello F., Bracco S., Sozzani P.: Modification of silica by liquid polybutadienes containing alkoxysilane groups. Macromolecular Symposia, 296, 550-556 (2010). https://doi.org/10.1002/masy.201051072

[16] Bertora A., Castellano M., Marsano E., Alessi M., Conzatti L., Stagnaro P., Colucci G., Priola A., Turturro A.: A new modifier for silica in reinforcing SBR elastomers for the tyre industry. Macromolecular Materials and Engineering, 296, 455-464 (2011).

https://doi.org/10.1002/mame.201000335

[17] Schapman F., Couvercelle J. P., Bunel C.: Low molar mass polybutadiene made crosslinkable by silane moities introduced via addition of thiol to double bond: 3 . Synthesis and kinetic study. Polymer, 39, 4955-4962 (1998). https://doi.org/10.1016/S0032-3861(97)10244-0

[18] Sirisinha K., Boonkongkaew M., Kositchaiyong S.: The effect of silane carriers on silane grafting of high-density polyethylene and properties of crosslinked products. Polymer Testing, 29, 958-965 (2010). https://doi.org/10.1016/j.polymertesting.2010.08.004

[19] Shieh Y-T., Tsai T-H.: Silane grafting reactions of lowdensity polyethylene. Journal of Applied Polymer Science, 69, 255-261 (1998).

https://doi.org/10.1002/(SICI)10974628(19980711)69:2<255::AID-APP6>3.0.CO;2-M

[20] Shieh Y-T., Liu C-M.: Silane grafting reactions of LDPE, HDPE, and LLDPE. Journal of Applied Polymer Science, 74, 3404-3411 (1999).

https://doi.org/10.1002/(SICI)10974628(19991227)74:14<3404::AID-APP14>3.0.CO;2-S
[21] Beltraán M., Mijangos C.: Silane grafting and moisture crosslinking of polypropylene. Polymer Engineering and Science, 40, 1534-1541 (2000).

https://doi.org/10.1002/pen.11283

[22] Payne A. R.: A note on the conductivity and modulus of carbon black-loaded rubbers. Journal of Applied Polymer Science, 9, 1073-1082 (1965).

https://doi.org/10.1002/app.1965.070090323

[23] Wolff S., Wang M-J., Tan E-H.: Filler-elastomer interactions. Part VII. Study on bound rubber. Rubber Chemistry and Technology, 66, 163-177 (1993).

https://doi.org/10.5254/1.3538304

[24] Pesetskii S. S., Jurkowski B., Krivoguz Y. M., Kelar K.: Free-radical grafting of itaconic acid onto LDPE by reactive extrusion: I. Effect of initiator solubility. Polymer, 42, 469-475 (2001).

https://doi.org/10.1016/S0032-3861(00)00356-6

[25] Lehrle R. S., Willist S. L.: Modification of natural rubber: a study to assess the effect of vinyl acetate on the efficiency of grafting methyl methacrylate on rubber in latex form, in the presence of azo-bis-isobutyronitrile. Polymer, 38, 5937-5946 (1997). https://doi.org/10.1016/S0032-3861(97)00157-2

[26] de Oliveira P. C., de Oliveira A. M., Garcia A., de Souza Barboza J. C., de Carvalho Zavaglia C. A, dos Santos A. M.: Modification of natural rubber: A study by ${ }^{1} \mathrm{H}$ NMR to assess the degree of graftization of polyDMAEMA or polyMMA onto rubber particles under latex form in the presence of a redox couple initiator. European Polymer Journal, 41, 1883-1892 (2005).

https://doi.org/10.1016/j.eurpolymj.2005.02.030

[27] Jiao C., Wang Z., Gui Z., Hu Y.: Silane grafting and crosslinking of ethylene-octene copolymer. European Polymer Journal, 41, 1204-1211 (2005).

https://doi.org/10.1016/j.eurpolymj.2004.12.008

[28] Abdelmouleh M., Boufi S., Belgacem M. N., Dufresne A.: Short natural-fibre reinforced polyethylene and natural rubber composites: Effect of silane coupling agents and fibres loading. Composites Science and Technology, 67, 1627-1639 (2007).

https://doi.org/10.1016/j.compscitech.2006.07.003

[29] Choi S-S.: Influence of mastication on properties of carbon black-filled NR compounds. Korea Polymer Journal, 8, 73-79 (2000).

[30] Ansarifar A., Shiah S. F., Bennett M.: Optimising the chemical bonding between silanised silica nanofiller and natural rubber and assessing its effects on the properties of the rubber. International Journal of Adhesion and Adhesives, 26, 454-463 (2006). https://doi.org/10.1016/j.ijadhadh.2005.06.008

[31] Schaal S., Coran A. Y.: The rheology and processability of tire compounds. Rubber Chemistry and Technology, 73, 225-239 (2000).

https://doi.org/10.5254/1.3547587 
[32] Choi S., Park B-H., Song H.: Influence of filler type and content on properties of styrene-butadiene rubber (SBR) compound reinforced with carbon black or silica. Polymers Advanced Technologies, 15, 122-127 (2004). https://doi.org/10.1002/pat.421

[33] Wolff S., Wang M-J.: Filler-elastomer interactions. Part IV. The effect of the surface energies of fillers on elastomer reinforcement. Rubber Chemistry and Technology, 65, 329-342 (1992). https://doi.org/10.5254/1.3538615

[34] Choi S-S., Nah C., Jo B-W.: Properties of natural rubber composites reinforced with silica or carbon black: Influence of cure accelerator content and filler dispersion. Polymer International, 52, 1382-1389 (2003). https://doi.org/10.1002/pi.1232

[35] Choi S-S.: Improvement of properties of silica-filled styrene-butadiene rubber compounds using acrylonitrile-butadiene rubber. Journal of Applied Polymer Science, 79, 1127-1133 (2001).

https://doi.org/10.1002/10974628(20010207)79:6<1127::AID-APP170>3.0.CO;2-8

[36] Lin C. Jr., Hergenrother W. L., Hilton A. S.: Mooney viscosity stability and polymer filler interactions in silica filled rubbers. Rubber Chemistry and Technology, 75, 215-245 (2002).

https://doi.org/10.5254/1.3544974

[37] Guy L., Daudey S., Cochet P., Bomal Y.: New insights in the dynamic properties of precipitated silica filled rubber using a new high surface silica. Kautschuk Gummi Kunststoffe, 62, 383-391 (2009).

[38] Kaewsakul W., Sahakaro K., Dierkes W. K., Noordermeer J. W. M.: Optimization of rubber formulation for silica-reinforced natural rubber compounds. Rubber Chemistry and Technology, 86, 313-329 (2013). https://doi.org/10.5254/RCT.13.87970

[39] Gauthier C., Reynaud E., Vassoille R., Ladouce-Stelandre L.: Analysis of the non-linear viscoelastic behaviour of silica filled styrene butadiene rubber. Polymer, 45, 2761-2771 (2004).

https://doi.org/10.1016/j.polymer.2003.12.081
[40] Da Costa H. M., Visconte L. L. Y., Nunes R. C. R., Furtado C. R. G.: Mechanical and dynamic mechanical properties of rice husk ash-filled natural rubber compounds. Journal of Applied Polymer Science, 83, 2331 2346 (2002).

https://doi.org/10.1002/app.10125

[41] Robertson C. G., Lin C. J., Rackaitis M., Roland C. M.: Influence of particle size and polymer-filler coupling on viscoelastic glass transition of particle-reinforced polymers. Macromolecules, 41, 2727-2731 (2008). https://doi.org/10.1021/ma7022364

[42] UNECE Regulation No 117: Testing method for measuring the wet grip index of $\mathrm{C} 1$ tyres; Proposed amendments. GRRF 71-10, p23 (2011).

[43] Arayapranee W., Na-Ranong N., Rempel G. L.: Application of rice husk ash as fillers in the natural rubber industry. Journal of Applied Polymer Science, 98, 3441 (2005).

https://doi.org/10.1002/app.21004

[44] Ismail H., Nordin R., Noor A. M.: Cure characteristics, tensile properties and swelling behaviour of recycled rubber powder-filled natural rubber compounds. Polymer Testing, 21, 565-569 (2002). https://doi.org/10.1016/S0142-9418(01)00125-8

[45] ten Brinke J. W., van Swaaij P. J., Reuvekamp L. A. E. M., Noordermeer J. W. M.: The influence of silane sulfur and carbon rank on processing of a silica reinforced tire tread compound. Rubber Chemistry and Technology, 76, 12-35 (2003). https://doi.org/10.5254/1.3547728

[46] Kaewsakul K., Dierkes W. K., Noordermeer J. W. M., Sahakaro K.: Use of disulfidebased silane coupling agents with compensation of sulfur in silica-reinforced natural rubber compounds. Kautschuk Gummi Kunststoffe, 65, 33-39 (2014).

[47] Wolff S.: Crosslinking of 1.5-diene rubbers by means of bis-(3-triethoxysilylpropyl)tetrasulfide. Kautschuk Gummi Kunststoffe, 30, 516-523 (1977). 